\title{
A mulher coronariopata no climatério após a menopausa: implicações na qualidade de vida.
}

\author{
Maria Elenita Corrêa de Sampaio Favarato
}

Dissertação de mestrado apresentada ao Departamento de Saúde Materno-Infantil da Faculdade de Saúde Pública da Universidade de São Paulo para obtenção do Grau de Mestre.

Área de concentração: Saúde Materno-Infantil.

Orientador: Prof. Dr. José Mendes Aldrighi

São Paulo

2000 
Autorizo, exclusivamente para fins acadêmicos e científicos, a reprodução total ou parcial desta dissertação, por processos fotocopiadores.

Assinatura:

Data: 


\section{Ofertas de Aninha \\ (Aos moços)}

Eu sou aquela mulher a quem o tempo muito ensinou.

Ensinou a amar a vida.

Não desistir da luta.

Recomeçar na derrota.

Renunciar a palavras e pensamentos negativos.

Acreditar nos valores humanos.

Ser otimista.

Creio numa força imanente que vai ligando a família humana

numa corrente luminosa

de fraternidade universal.

Creio na solidariedade humana.

Creio na superação dos erros

e angústias do presente.

Acredito nos moços.

Exalto sua confiança, generosidade e idealismo.

Creio nos milagres da ciência

e na descoberta de uma profilaxia

futura dos erros e violências

do presente.

Aprendi que mais vale lutar do que recolher dinheiro fácil.

Antes acreditar do que duvidar.

(Cora Coralina,1984)

Ana Lins dos Guimarães é o nome de Cora Coralina, poetisa goiana, publicou o primeiro livro aos 80 anos. 


\section{AGRADECIMENTOS}

Ao Prof. Dr. José Mendes Aldrighi pela valiosa orientação e principalmente pelo relacionamento estabelecido durante a realização deste trabalho, baseado na confiança, incentivo e amizade.

À Profa. Dra. Bellkiss Wilma Romano, diretora do Serviço de Psicologia do InCor, que acompanha e incentiva meu percurso profissional desde o início.

Aos médicos dos grupos de coronariopatias e aterosclerose, Antonio de Pádua Mansur, Cícero Albuquerque Piva e Desidério Favarato pela colaboração na seleção das pacientes coronariopatas.

Ao Centro de Saúde Escola Geraldo de Paula Souza da FSP - USP, pela receptividade possibilitando a coleta de dados para o grupo controle.

À Andrea Larissa Ribeiro Pires, pela colaboração carinhosa na seleção das pacientes do grupo controle.

Ao Rogério dos Santos Angelo, secretário do Serviço de Psicologia do InCor, pela disponibilidade para colaborar. 
Às bibliotecárias da Faculdade de Saúde Pública pela atenciosa revisão das referências bibliográficas.

Às mulheres que participaram deste estudo, cuja contribuição foi fundamental. 


\section{RESUMO}

O climatério, período da vida da mulher situado entre os 35 e 65 anos, constitui uma transição entre a fase reprodutiva e a não reprodutiva. Diversas mudanças fazem parte desse período, como a menopausa, alteração da estética física, nos aspectos psicológicos e sociais.

No climatério há perda da proteção do estrogênio, ocorrendo aumento significativo na incidência de doenças cardiovasculares, que, após algumas décadas, alcança aquela observada homens. A cardiopatia pode promover um comprometimento global do indivíduo afetando-o, também, nos segmentos afetivo-emocional e social. A sobreposição de duas situações que envolvem importantes aspectos psicossociais - o fim do período reprodutivo e a presença da doença cardiovascular - pode interferir negativamente na qualidade de vida dessas mulheres.

$\mathrm{O}$ presente estudo avaliou a qualidade de vida em mulheres com doença isquêmica do coração no climatério após a menopausa. O estudo incluiu 100 mulheres após a menopausa, sendo 50 portadoras de doença arterial coronária (DAC) em seguimento no Instituto do Coração (InCor) HC-FMUSP e 50 que não apresentavam doenças associadas (grupo controle) atendidas no Centro de Saúde Escola Geraldo de Paula Souza da FSP - USP.

A qualidade de vida foi avaliada mediante a utilização de dois instrumentos: uma entrevista estruturada e a aplicação do questionário genérico de avaliação de qualidade de vida ( SF - 36 ). Os grupos eram homogêneos em relação à idade da última menstruação: $49 \pm 3,9$ anos na DAC e $49,2 \pm 3$ anos no grupo controle. Os grupos também eram similares quanto à escolaridade: $84 \%$ possuíam primeiro grau (completo ou incompleto); estado civil: casadas $64 \%$ das DAC e $45 \%$ do grupo controle e viúvas $18 \%$ da DAC e $24 \%$ das controle. A atividade profissional fora do lar foi significativamente mais frequente no grupo controle (52\%) e $14 \%$ nas DAC $(\mathrm{p}=0,0001)$. Ambos os grupos demonstraram percepções semelhantes no que se refere a sexualidade. A avaliação da qualidade de vida pelo SF - 36 mostrou melhores resultados no grupo controle em relação a: capacidade física ( 84 vs 50,5 na DAC); aspectos físicos ( 84 vs 45,5); estado geral de saúde (87,2 vs 59,1$)$; vitalidade $(69,7$ vs 51,4$)$ e escore total dos componentes mentais $(70,4$ vs 58,6$)$.

Tais resultados nos levaram à conclusão que a coronariopatia interfere na qualidade de vida das mulheres após a menopausa, limitando a capacidade física e o desempenho das atividades da vida diária, além de intensificar as dificuldades emocionais desse período. 


\section{SUMMARY}

Climaterium, the life period of women ranging from 35 to 65 years old, includes the transitional phase between the reproductive to the non-reproductive life period. It is a great challenging period in a woman's life: everything is changing, the menses stop, sexual hormone levels decline, physical strength and activity decrease, and important psychological and social role changes occur.

The declining levels of estrogen are associated with an increase in cardiovascular disease incidence that, after some decades, reaches similar rates as men in climacteric women. All chronic diseases, particularly coronary artery disease, compromise the patient as a whole, including physical, affective-emotional and social aspects. Therefore, the overlap of two different stressful situations; the end of the reproductive life and the presence of coronary artery disease, may negatively influence the quality of life in women.

The aim of this study was to analyse the quality of life of post menopausal women with coronary artery disease. The population consisted of 100 women, 50 (58 \pm 4.2 years old) with stable angiography provess coronary artery disease (CAD) undergoing treatment at The Heart Institute (InCor) - University of São Paulo medical school, Brazil (CAD group). This group was compared with 50 women $(55.1 \pm 5.4$ years old) without clinical evidence of coronary artery disease (control group) from a primary health care center, Centro de Saúde Escola Geraldo de Paula Souza, São Paulo - FSP- USP. The quality of life was assessed by a structured interview and by Medical outcomes study 36-item short-form health survey (SF-36) validated to the Brazilian population. They were homogenous regarding age of the last menstruation period: $49 \pm 3.9$ years old in CAD and $49.2 \pm 3$ years old in controls. The groups were also similar in education level, marital status (64\% of CAD and $45 \%$ of controls were married; and $18 \%$ of $\mathrm{CAD}$ and $24 \%$ of controls were widowhood). The active working satatus was more frequent in controls than in CAD (52\% vs. $14 \%$; $\mathrm{p}=0.0001)$. Both groups showed similar perceptions in their sexual experience. The evaluation of quality of life by SF-36 showed better scores for the control group in: physical functioning ( 84 vs. 50.5), role physical ( 84 vs. 45,5$)$, general health (87.2 vs. 59.1$)$, vitality ( 69.7 vs. 51,4$), \mathrm{p}<0.0001$; and total score of mental components $(70.4$ vs. 58.6), $\mathrm{p}=0.028$.

Coronary artery disease alters the quality of life of climacteric women by limiting the physical capacity to perform ordinary daily activities and by intensifying emotional conflicts usually present in this phase of life. 


\section{ÍNDICE}

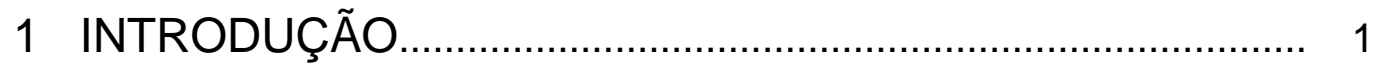

1.1 Formação do conceito "mulher"........................................... 3

$1.2 \mathrm{O}$ climatério e suas repercussões.......................................... 5

1.3 Aspectos emocionais da cardiopata....................................... 9

1.4 Conceito de qualidade de vida.............................................. 12

1.5 O binômio cardiopatia e climatério como foco de
interesse na área de saúde..................................................... 14

2 OBJETIVO

3 MÉTODO

3.1 Delineamento do estudo.................................................... 17

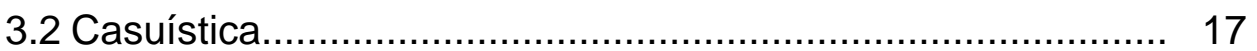

3.3 Coleta de dados ............................................................ 17

3.3.1 Procedimentos.................................................. 17

3.3.2 Instrumentos................................................... 18

A - Entrevista estruturada.................................. 18

B - Questionário genérico de avaliação de qualidade de vida (SF-36) ................................ 18

3.4 Procedimentos estatísticos.............................................. 20

4 RESULTADOS

5 DISCUSSÃO

6 CONCLUSÕES ...................................................................... 57

7 REFERÊNCIAS ............................................................. 58

ANEXOS

Anexo 1 - Termo de consentimento livre e esclarecido

Anexo 2 - Roteiro de entrevista estruturada

Anexo 3 - Questionário genérico de avaliação de qualidade de vida (SF-36) 


\section{INTRODUÇÃO}

A palavra climatério originada do grego "klimater", significa degrau e era utilizada para designar qualquer época da vida considerada crítica (BIFFI, 1991). Atualmente, o climatério é definido como a fase da vida da mulher na qual ocorre a transição entre o período reprodutivo e o não reprodutivo, com o aparecimento de expressivas modificações biopsicossociais; tem início aos 35

e término aos 65 anos. Menopausa é a última menstruação e só é diagnosticada após um intervalo de doze meses sem menstruação. Síndrome climatérica é o elenco de sintomas que se manifesta nesse período (FEBRASGO, 1995).

A menopausa natural ocorre em torno dos 50 anos de idade, sendo que o período compreendido entre 12 e 24 meses antes da última menstruação, representa a perimenopausa (ALDRIGHI, 1996).

Com a instabilidade hormonal, surgem no climatério manifestações precoces, de médio prazo e tardias, que repercutem em nível biológico, psicológico e social. As precoces compreendem alterações menstruais, ondas de calor, sudorese, calafrios, cefaléia, tonturas, parestesias, palpitações, fadiga, insônia, perda de memória e depressão. Dentre as de médio prazo, destacam-se a secura vaginal, dispareunia, incontinência urinária e perda de colágeno na pele; as modificações tardias decorrem de alterações metabólicas e podem levar à doença cardiovascular e osteoporose (MINISTÉRIO DA SAÚDE, 1994). 
Em relação às manifestações precoces, sabe-se que elas decorrem da diminuição da atividade ovariana e subsequente deficiência hormonal, mas também de dois outros fatores, os sócio-culturais determinados pelo meio ambiente e os psíquicos, dependentes da personalidade da mulher (APPOLINÁRIO et al, 1992).

Estudo de SKULTANS ( 1979), considera que a menopausa se constitui em um "rito de passagem", ou seja a mulher assume outro papel social. Assim, aquelas que atribuem pouca importância à menstruação não sentem a mudança de papel que desempenham; considera, dessa forma, que a menopausa é mais sócio-cultural do que biológica.

Apesar do significativo aumento da expectativa de vida e longevidade ocorrida a partir do século XX, em alguns países desenvolvidos alcança os 80 anos, a data de instalação da menopausa permanece inalterada, ou seja, em torno dos 50 anos. Isto representa que neste milênio um maior número de mulheres poderá viver 30 a 40 anos em uma condição de importante redução de produção hormonal (BYYNY, 1996), que propiciará um incremento na prevalência de doenças como a cardiovascular, a osteoporose, os cânceres de mama e útero e os distúrbios da função cognitiva.

O interesse pelo tema surgiu a partir de reflexões que foram suscitadas no atendimento psicológico a mulheres coronariopatas no climatério, no Instituto do Coração - InCor - HCFMUSP, que vivenciam concomitantemente situações de perdas muito significativas. Assim, com a doença deparam-se com a perda da saúde e o medo da morte, muitas vezes acompanhados de mudanças nos 
papéis social e profissional, além de alterações na dinâmica familiar. $O$ climatério, por sua vez, também incrementa mudanças físicas, psíquicas e sociais.

A escassez de estudos na literatura sobre o binômio cardiopatia e climatério, envolvendo repercussões psicológicas sobre a qualidade de vida, acentuou ainda mais o interesse pelo tema.

\subsection{Formação do conceito "mulher"}

Para a formação da imagem feminina e do conceito "ser mulher", três elementos são determinantes e se interelacionam: os biológicos, os psicológicos e os culturais. Os elementos biológicos, tais como a ação dos hormônios no determinismo dos caracteres sexuais secundários, não só influenciam na formação da auto-imagem feminina, mas também se responsabilizam por mudanças marcantes na vida, como a puberdade, maternidade e menopausa.

A puberdade é um processo de maturação sexual que transforma o corpo infantil em um corpo biológicamente maduro, capaz da reprodução sexual. Ocorre, em geral, aos 11 anos, tendo como marco fundamental a menarca, que corresponde ao primeiro período menstrual (ATKINSON et al, 1993).

A maternidade por sua vez, envolve mudanças biológicas e fisiológicas significativas. O corpo feminino, durante as 40 semanas, muda intensa e 
rapidamente, interferindo no emocional da mulher, com a eclosão de sentimentos de responsabilidade, dúvidas, insegurança, felicidade, etc.

Finalmente, a menopausa é o marcador biológico do início de um processo de modificações biopsicossociais, sendo parte integrante do processo de envelhecimento (ALDRIGHI, 1996).

A identidade feminina é construída a partir do nascimento, decorrente da relação direta mãe-filha; assim, os elementos são adquiridos, internalizados pela criança e formam a base da personalidade feminina.

Para se compreender melhor o desenvolvimento da personalidade feminina, faz-se necessário a distinção entre gênero sexual, sexo, papel sexual e social. O gênero sexual é um sinal, ou seja, é tudo aquilo que uma pessoa diz ou faz para indicar se é homem ou mulher; dessa forma, a biologia e a hereditariedade são os responsáveis pelo sexo e a sociedade, a cultura e a época pelo gênero sexual.

O papel sexual também é determinado pela sociedade, uma vez que representa a expectativa em torno dos dois diferentes gêneros sexuais. Isto é, a sociedade atribui valores, regras, caminhos a serem seguidos pelos diferentes gêneros e espera que as pessoas correspondam e apresentem atitudes equivalentes aos valores por ela determinados.

Em última instância, surge o papel social que é a forma de agir e ser na sociedade, essa forma de ação é apreendida ao longo do processo evolutivo e deriva-se da determinação dos papéis sexuais. 
Segundo KUSNETZOFF (1988), a natureza só traz a anatomia e a fisiologia; tudo mais é produto de cada cultura e sociedade. Os papéis sociais são aprendidos no processo evolutivo de todo ser humano. Homens e mulheres tendem a se adaptar, a fazer o que deles se espera, ou seja, a cumprir o papel que a sociedade Ihes atribui.

Não se pode deixar de refletir sobre o contexto sócio-cultural em que ocorreu a história pessoal das mulheres que hoje estão no climatério. As mulheres que vivem o climatério nos anos 90 são de uma geração de transição com grande mudança dos valores sociais e papéis femininos, conviveram com mudanças no casamento, menos submissão; na maternidade, a opção por ter filhos mais tarde; na profissão, necessidade a ser sujeito e na educação dos filhos, mais liberalidade (FAVARATO et al, 1999).

\subsection{0 climatério e suas repercussões}

No início deste século, apenas $6 \%$ das mulheres atingiam a menopausa e estima-se que no ano $2025,23 \%$ da população dos países desenvolvidos estará com mais de 60 anos (BYYNY, 1996).

Culturalmente, a menopausa representa um marco na determinação de mudanças na vida da mulher, inclusive em seu papel social. Por outro lado, a menopausa propicia sintomas desconfortáveis e aumento na incidência de doenças. Entre elas destaca-se a doença cardiovascular, que de fato é mais prevalente, quando comparada com a fase pré-menopausa (WENGER, 1996). 
Estudos epidemiológicos (KANNEL et al.; FRAMINGHAM STUDY- 1976) demonstraram que com a idade as mulheres apresentam aumento progressivo na incidência da doença isquêmica do coração (DIC); assim, após a menopausa o risco da DIC se eleva, aproximando-se ao dos homens em torno dos 65 anos.

A doença isquêmica do coração ocorre por lesão aterosclerótica das artérias coronárias, isto é, deposição de lipídeos em forma de placas nas paredes dos vasos, que diminuindo seu calibre, pode causar obstrução da artéria.

Os fatores implicados na gênese da DIC incluem a elevação dos lipídeos séricos, a hipertensão arterial, o tabagismo, o diabetes, a obesidade, o sedentarismo, o estresse, os antecedentes familiares e a própria menopausa, que, com a redução de estrogênios, acelera o depósito de lipídeos nas paredes das artérias.

Em relação aos aspectos emocionais do climatério deve-se considerar que a menstruação, por indicar simbolicamente fertilidade e saúde, apresenta grande significado por proporcionar não só "status", mas também poder diante da perpetuação da espécie; seu término pode ser interpretado como o fim da idade saudável, da reprodução e o início do declínio biológico.

As reações emocionais no climatério são variáveis; de fato, muitas mulheres vivenciam esse período de forma assintomática ou com sintomas inexpressivos, entendendo-o como o início de uma nova etapa, ou seja, a de amadurecimento existencial que Ihes permitirão uma vida com maior segurança e confiança; outras porém, vivenciam-o de forma negativa e apresentam vários 
sintomas e queixas psíquicas, destacando-se a irritabilidade, ansiedade, depressão e as disfunções sexuais (alterações do desejo, da excitação e do orgasmo). Os sintomas são mais exacerbados em mulheres que perderam seu papel social e não redefiniram seus objetivos existenciais (ABREU, 1992).

DENNERSTEIN (1978), por sua vez, relatou que fatores da personalidade e tendências ansiosas correlacionam-se com maior número de queixas psicológicas.

É interessante considerar as observações de THONET (1985) que encara o climatério como uma forma de transição, semelhante a uma segunda adolescência. Realmente nestas duas etapas de vida há mudanças hormonais e de adaptação. Assim, no que tange à adaptação, a adolescente enfrenta as modificações com a vitalidade de um organismo em pleno desenvolvimento e com energia de quem tem metas a alcançar, diferentemente da mulher no climatério que pode apresentar falta de motivações para se adaptar a esta nova fase, bem como baixo entusiasmo para alcançar metas. A desmotivação é claramente percebida em mulheres que não possuem novos objetivos existenciais que as estimulem a prosseguir suas vidas.

DEUSTSCH (1944), por sua vez compara os conflitos da menopausa com os da menarca; assim, relata inquietudes sobre mudanças em seu corpo, sobre a sexualidade e sobre sua atividade social. Ressalta, no entanto, que esses conflitos são variáveis de acordo com a estrutura psicológica da mulher e que não são obrigatórios no climatério (BENEDEK e RUBINSTEIN, 1952). 
É interessante considerar que as situações conflitivas observadas no climatério podem comprometer a auto-estima; isto, talvez, se explique pelo fato de muitas delas associarem o término da capacidade reprodutiva com a velhice e proximidade da morte, entendendo que o climatério passaria a ser um marco de perdas, de objetivos, metas, funções sociais e de ser jovem.

Convém ressaltar que nas sociedades ocidentais, o aspecto físico e a beleza feminina são supervalorizados; daí, é compreensível que mudanças nesses atributos acarretem impacto negativo na auto-percepção da mulher, gerando preocupação com o envelhecimento corporal.

SCHINDLER (1987) considera que as doenças depressivas são as desordens psiquiátricas mais prevalentes da metade para a última fase da vida, sendo que as mulheres são mais vulneráveis do que os homens.

A correlação entre depressão e climatério ainda é assunto controverso; trata-se de questão complexa pois durante esse período outras inquietudes tornam-se evidentes, tais como o envelhecimento, a morte dos pais, a saída dos filhos de casa em busca de independência e a dificuldade no relacionamento conjugal após muitos anos de vida em comum. Essas intercorrências podem provocar uma reavaliação de seus papéis de mãe e mulher, fazendo-a deparar-se com questionamentos relacionados a sua existência pregressa e futura. O confronto, não raro pela primeira vez, com a questão da própria morte, pode gerar um desequilíbrio em sua estrutura psíquica. 


\subsection{Aspectos emocionais da cardiopata}

A cardiopatia promove um comprometimento geral no indivíduo, afetando-o nos segmentos afetivo-emocional, intelectual e social; além do mais, por ser uma afecção ameaçadora, gera medo, ansiedade e insegurança, sinalizando para o indivíduo sua vulnerabilidade e finitude.

Por outro lado, não se pode esquecer o simbolismo do coração; de fato, é inegável que entre todos os órgãos do corpo, o coração foi sempre o escolhido para denotar sentimentos, apesar de existir outros órgãos "nobres", como por exemplo, o cérebro, centro do pensamento e da lógica. Segundo LAMOSA (1990) são infindáveis as citações religiosas, filosóficas, folclóricas, pictóricas, mitológicas, nas quais aparece o coração, símbolo universal, como sede de emoções, de vida, de objeto-síntese da pessoa. Portanto, adoecer de um órgão que encerra sentimentos tão importantes, como amor, paixão e ódio, pode acarretar repercussões emocionais marcantes.

De acordo com a personalidade da paciente e com a intensidade da doença somática, as respostas emocionais caracterizam-se por atitudes passivas e regressivas, acarretando perda de independência e autonomia; outras vezes, há comportamentos de oposição, animosidade e desconfiança. Acrescenta-se, ainda, a mudança de papéis sociais que a cardiopatia promove no âmbito familiar, profissional e social.

ROZANSKI et al (1999) relatam que há cinco fatores psicossociais que contribuem de forma significativa para a etiopatogenia e expressão da doença 
isquêmica do coração; incluem a, depressão, ansiedade, personalidade competitiva, o isolamento social e o estresse crônico.

As evidências que correlacionavam a ansiedade com a DIC eram limitadas à constatação de elevada mortalidade em pacientes psiquiátricos com ansiedade; atualmente, verifica-se expressivo número de estudos que associam a ansiedade com a ocorrência de eventos cardíacos na população geral (HAINES, 1987; KAWACHI, 1994).

FRIEDMAN e ROSENMAN (1959) ao estudarem padrões de personalidade, identificaram um, denominado tipo $A$, que se caracteriza predominantemente por competição, hostilidade e exagerada vinculação ao trabalho e que se associa frequentemente com o desenvolvimento da DIC.

Nessa linha de pesquisa a literatura tem desvelado estudos que relacionam traços do caráter individual com a DIC; assim, a hostilidade, maior atributo do padrão de personalidade "tipo A", tem merecido especial atenção como o principal elemento dessa construção de personalidade. A hostilidade interfere nos relacionamentos interpessoais e inclui traços como raiva, cinismo e desconfiança (KING, 1997).

O estresse crônico relacionado a DIC tem sido amplamente estudado, destacando-se aquele ligado à tensão no trabalho com alta demanda, baixo poder de decisão, pouca recompensa e ausência controle sobre o trabalho.

O acumulo de situações estressantes no dia a dia e sua possível relação com a DIC estimulou HOLMES e RAHE (1967) a desenvolverem um questionário denominado "Questionário de eventos vitais" que visa identificar os eventos 
ocorridos no último ano, tais como morte do parceiro, divórcio e perda de emprego, entre outros; a cada um deles atribuía-se um valor. Baseado nesse questionário, RAHE et al (1974) observaram nítida associação entre infarto do miocárdio e morte súbita no período de seis meses após a ocorrência dessas situações estressantes.

Quando o indivíduo é acometido de um agravo à saúde, várias reações depressivas podem eclodir a partir de fatores pessoais, como por exemplo sentimentos de culpa, negação e reestruturação da escala de valores; portanto, o surgimento da cardiopatia pode predispor o estabelecimento ou fortalecimento de uma configuração depressiva.

Estudos epidemiológicos recentes demonstram de forma consistente uma relação significante entre episódios de depressão maior e incidência de eventos cardíacos (SCHLEIFER et al, 1989). Por outro lado, sabe-se que a presença de sintomas depressivos, na ausência de diagnóstico de depressão maior, também se associa com elevação do risco de eventos cardíacos; além do mais, há uma nítida relação entre magnitude da depressão e evento cardíaco( ANDA et al, 1993 ).

Deve, ainda, ser destacado que além da cardiopatia poder alterar a dinâmica psíquica da paciente, o climatério "per se" pode representar uma outra situação estressante para o contexto psíquico da mulher.

\subsection{Conceito de qualidade de vida}


Qualidade de vida é conceito originário das ciências sociais, resultado de várias medidas provenientes de indicadores biopsicossociais. A quantificação da qualidade de vida deve obedecer aos seguintes tópicos: trabalho/condições de trabalho, recursos econômicos, escolaridade, saúde/acesso aos serviços de saúde, relações familiares, habitação, nutrição e lazer.

Cada um desses tem seus desdobramentos; assim, na análise da saúde, devem ser incluídos cinco conceitos gerais: saúde física, saúde mental, funções sociais, desempenho de papéis e percepção geral da saúde, que permitem uma melhor determinação do desempenho das atividades diárias e do seu bem estar (FLANAGAN, 1982; WARE, 1987).

A conceituação de qualidade de vida vem sofrendo modificações, partindo-se de uma visão eminentemente biológica para conceitos multidimensionais, onde são incluídas áreas com características mais subjetivas, como atividade social, estado psicológico e expectativas sobre o tratamento (FLETCHER, 1987).

ROMANO (1993) enfatiza a necessidade em se diferenciar "nível de vida" e "qualidade de vida". Enquanto nível de vida depende primordialmente de definições e perspectivas políticas, portanto voltado a comunidade como um todo, qualidade de vida é um atributo do indivíduo.

A Organização Mundial de Saúde (WHOQOL GROUP, 1994) define qualidade de vida como "a auto-percepção do indivíduo, no contexto da cultura e nos sistemas de valores em que ele vive, correlacionando com seus objetivos, expectativas, padrões e preocupações". Nessa definição está implícito que 
qualidade de vida é conceito subjetivo, multidimensional e que inclui elementos de avaliação tanto positivos como negativos.

Diversos instrumentos ou índices têm sido propostos e utilizados com a finalidade de avaliar a qualidade de vida de pacientes com os mais diversos problemas de saúde; dividem-se em dois grupos, os genéricos e os específicos (PATRICK \& DEYO, 1989; KATZ et al, 1992; BARR, 1995; GUYATT, 1995; GUYATT et al, 1997).

Os instrumentos genéricos foram desenvolvidos com a finalidade de refletir sobre o impacto de uma doença na vida de pacientes em uma ampla variedade de populações; avaliam aspectos relativos a função, disfunção e desconforto físico e emocional.

Os instrumentos específicos são capazes de avaliar de forma individual e específica determinados aspectos da qualidade de vida, proporcionando uma maior capacidade de detecção de melhora ou piora do aspecto em estudo. Sua principal característica é seu potencial de ser sensível às alterações, ou seja, a capacidade que possui de detectar mudanças após uma determinada intervenção. De acordo com GYATT (1995), podem ser específicos para uma determinada função (capacidade física, sono, função sexual), para uma determinada população (idosos, jovens) e para uma determinada alteração (dor). 


\section{5 binômio cardiopatia e climatério como foco de interesse na área de saúde}

Cardiopatia e climatério estão vinculados a forte simbologia. Coração, centro da vida e das emoções e menstruação, símbolo de fertilidade e saúde da mulher. As reações emocionais a esses dois eventos podem ser positivas, ou seja a mulher cardiopata vivencia uma fase de reformulação de valores, mudanças de hábitos e estilo de vida, caminhando para um amadurecimento e crescimento existencial; por outro lado, podem ser negativas, com supervalorização das perdas e falta de reestruturação do processo vital.

Sabe-se que a estrutura prévia da personalidade e a forma como a mulher enfrentou anteriormente outras situações de perdas e crises são determinantes importantes na forma de reagir ao binômio cardiopatia e climatério.

A importância dos fatores psicossociais e a magnitude do problema que envolvem a cardiopatia e o climatério são evidentes. Garantir condições para que essas mulheres vivam com independência e qualidade deve ser o foco de preocupação.

Do exposto e face à escassez de estudos que avaliam a qualidade de vida em mulheres coronariopatas na pós-menopausa propusemo-nos a estudá-la. 


\section{OBJETIVO}

Avaliar a qualidade de vida em mulheres portadoras de doença isquêmica do coração no climatério após a menopausa. 


\section{MÉTODO}

\subsection{Delineamento do estudo}

Estudo caso-controle, do tipo observacional analítico.

\subsection{Casuística}

O estudo incluiu 100 mulheres no climatério após a menopausa (última menstruação há mais de um ano) e com idade inferior à 65 anos. Foram divididas em dois grupos: o A composto por 50 mulheres, portadoras de doença arterial coronária, comprovada por cinecoronariografia, que faziam seguimento ambulatorial no Instituto do Coração - InCor - HCFMUSP, vinculadas ao SUS e que não estavam em terapia de reposição hormonal $(\mathrm{TRH})$ e o $\mathbf{B}$, composto por 50 usuárias do Centro de Saúde Escola Geraldo de Paula Souza, da Faculdade de Saúde Pública - USP, que não apresentavam doenças associadas e também não estavam em uso de terapia de reposição hormonal.

\subsection{Coleta de dados}

\subsubsection{Procedimentos}

A qualidade de vida foi avaliada mediante a utilização de dois instrumentos: uma entrevista estruturada e um questionário genérico de avaliação de qualidade de vida, elaborado para pesquisa em saúde, e denominado "Questionário genérico de avaliação de qualidade de vida (SF-36)". 
Cabe ressaltar que a avaliação foi realizada por um único pesquisador, após a obtenção do termo de consentimento livre e esclarecido.

\subsubsection{Instrumentos}

\section{A - Entrevista estruturada}

A entrevista teve por objetivo avaliar a mulher, com enfoque para diferentes aspectos tais como, a vida familiar, atividade profissional, social, de lazer e esportiva, os aspectos emocionais, a auto-imagem, a saúde, os sintomas ligados ao climatério, a sexualidade e a percepção da qualidade de vida.

\section{B - Questionário genérico de avaliação de qualidade de vida (SF-36)}

O SF-36 foi construído por WARE e SHERBOUNE (1992) para pesquisar o estado de saúde na prática clínica e nas pesquisas em populações. Esse questionário consta de múltiplos itens, podendo ser aplicado a partir dos 14 anos de idade e tem o propósito de avaliar oito domínios divididos em dois grandes componentes: o físico, (envolve a capacidade funcional, os aspectos físicos, a dor e o estado geral da saúde)e o mental, (abrange a saúde mental, os aspectos emocionais, sociais e a vitalidade); o estado geral da saúde e a vitalidade estão indiretamente relacionados aos dois segmentos.

A seguir, detalham-se o que visa a avaliação dos componentes físicos do SF-36. Na capacidade funcional, avalia-se a presença e a extensão das limitações relacionadas à capacidade física com três níveis de resposta (muita 
limitação, pouca e sem limitação); os aspectos físicos são avaliados pelas limitações físicas na realização do trabalho e das atividades diárias. A dor, é pesquisada por meio de sua intensidade, extensão e/ou interferência nas atividades diárias; o estado geral de saúde é avaliado pela auto-percepção.

Em relação aos componentes mentais, a vitalidade é avaliada pelo nível de energia e fadiga na realização das atividades da vida diária. Os aspectos sociais são avaliados pela integração do indivíduo nas atividades sociais; os emocionais, pelas dificuldades emocionais que limitam $o$ trabalho $e$ as atividades da vida diária e a saúde mental pela presença de ansiedade, depressão, alterações de comportamento ou descontrole emocional e bemestar psicológico.

Apesar do SF-36 ter sido elaborado para ser um instrumento autoadministrável, a aplicação em nossa população foi realizada por meio de entrevistas, em função do nível de escolaridade das usuárias do Ambulatório do InCor e do Centro de Saúde Escola Geraldo de Paula Souza.

Tal fato se embasa nas observações de WEINBERGER et al (1996), que ao compararem várias formas de aplicação do SF-36, ou seja, por meio de telefonemas, entrevistas ou pela forma auto-administrável observaram resultados semelhantes entre as três formas de aplicação; porém, no que se refere à preferência dos pacientes, a forma de aplicação através de entrevista foi a principal escolha (70\%), seguida pela auto-administravel $(20 \%)$ e pelos telefonemas (10\%). 
O SF-36 foi traduzido para o português e validado para nossa população (CICONELLI, 1997).

\subsection{Procedimentos estatísticos}

O tamanho da amostra foi calculado com base em estudo anterior que utilizou o SF 36, em mulheres no climatério não portadoras de doenças (WILSON, et al, 1998).

Nossa hipótese era que as coronariopatas na pós-menopausa, quando avaliadas pelo SF-36, teriam a qualidade de vida prejudicada em seus componentes físicos e mentais, comparadas àquelas na pós-menopausa sem a presença de doença.

$\mathrm{Na}$ expectativa desses resultados inferiores nas portadoras de doença coronária, com nível de significância de 5\% e poder beta de $80 \%$ para distinguir diferença de $30 \%$ entre os dois subgrupos foram elaborados os cálculos estatísticos e definiu-se a amostra necessária.

Para o tratamento estatístico dos dados utilizou-se a Análise Descritiva Univariada: freqüência, média e desvio padrão para as variáveis contínuas e a mediana para as variáveis categóricas.

Para comparação entre os subgrupos, avaliou-se a existência de associação entre as variáveis. As contínuas foram analisadas através do Teste t de Student e as categóricas por testes não paramétricos: Qui-quadrado, Teste Exato de Fischer e Teste da Mediana. 


\section{RESULTADOS}

No grupo A (coronariopatas), a idade variou de 49 à 64 anos, com média de 58 anos, desvio padrão 4,17 anos e mediana de 58,5 anos.

No grupo B (controle), a idade variou de 44 à 64 anos, com média 55,1 anos, desvio padrão de 5,38 anos e mediana de 55 anos.

A média da diferença de idade entre os dois grupos foi de 2,9 anos, desvio padrão 0,9 anos, sendo as coronariopatas mais idosas $(p=0,003)$.

A média e mediana da idade em que ocorreu a menopausa (última menstruação) foi semelhante nos dois grupos; 49 anos, com desvio padrão de 3,9 anos nas coronariopatas e 49,2 anos, com desvio padrão de 3 anos nas mulheres do grupo controle $(p=0,8)$.

Quanto ao tempo pós menopausa as coronariopatas tinham em média 9 anos, com desvio padrão 0,71 anos e as do grupo controle 5,9 anos com desvio padrão 0,73 anos $(p=0,003)$.

Quanto a escolaridade, $84 \%$ das portadoras de doença coronária e das mulheres do grupo controle possuíam $1^{\circ}$ grau (completo ou incompleto). (Figura 1) 
Figura 1 - Distribuição das pacientes segundo escolaridade.

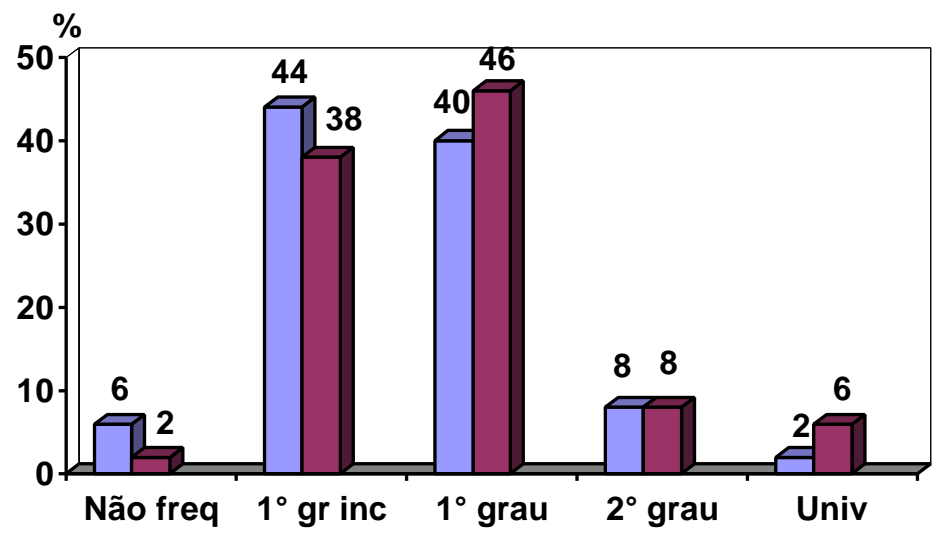

$\square$ Coronariopatas

$\square$ Controle

No que se refere a profissão, as coronariopatas desenvolviam mais frequentemente prendas do lar (68\%), enquanto que nas mulheres do grupo controle foi $28 \%$, e apresentavam ocupações mais variadas. Esta diferença foi estatisticamente significante com $p=0,003$ (Tabela 1).

Tabela 1 - Distribuição das pacientes segundo profissão.

\begin{tabular}{|c|c|c|c|c|c|}
\hline \multirow[t]{2}{*}{ Profissão } & \multicolumn{2}{|c|}{ Coronariopatas } & \multicolumn{2}{|c|}{ Controles } & \multirow{2}{*}{$\begin{array}{c}\text { Total } \\
\text { № }\end{array}$} \\
\hline & No & $\%$ & № & $\%$ & \\
\hline Prendas do lar & 34 & $68 \%$ & 14 & $28 \%$ & 48 \\
\hline Aposentada & 5 & $10 \%$ & 5 & $10 \%$ & 10 \\
\hline Aposentada invalidez & 2 & $4 \%$ & & & 2 \\
\hline Empregada doméstica & 1 & $2 \%$ & 14 & $28 \%$ & 15 \\
\hline Cozinheira & & & 3 & $6 \%$ & 3 \\
\hline Costureira & 2 & $4 \%$ & 2 & $4 \%$ & 4 \\
\hline Atendente enfermagem & 1 & $2 \%$ & 2 & $4 \%$ & 3 \\
\hline Outras profissões & 5 & $10 \%$ & 10 & $20 \%$ & 15 \\
\hline
\end{tabular}

Quanto ao estado civil, $64 \%$ das coronariopatas e $46 \%$ do grupo controle eram casadas, diferença não significativa, $p=0,11$ (Figura 2). 
Figura 2 - Distribuição das pacientes segundo estado civil.

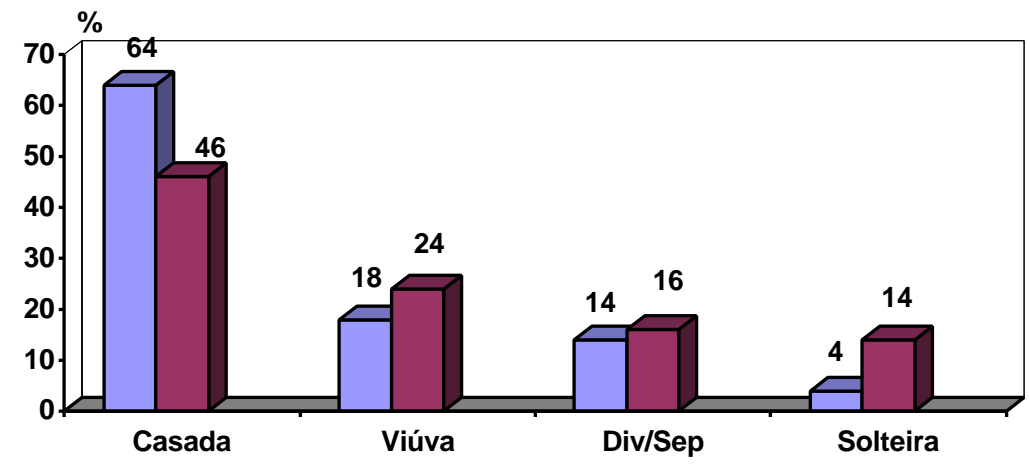

$\square$ Coroariopatas aControle

A entrevista estruturada revelou os seguintes dados:

\section{Vida familiar}

Entre as coronariopatas, $70 \%$ tinham companheiro e no grupo controle, $58 \%$.

Quando questionadas a respeito da qualidade deste relacionamento, 48,6\% das coronariopatas consideraram bom e 51,5\% regular ou ruim. No grupo controle, $48,3 \%$ classificaram como bom e $51,7 \%$ regular ou ruim. As diferenças em relação a vida familiar não foram estatisticamente significantes (Figura 3). 
Figura 3 - Distribuição das pacientes segundo qualidade do relacionamento conjugal.

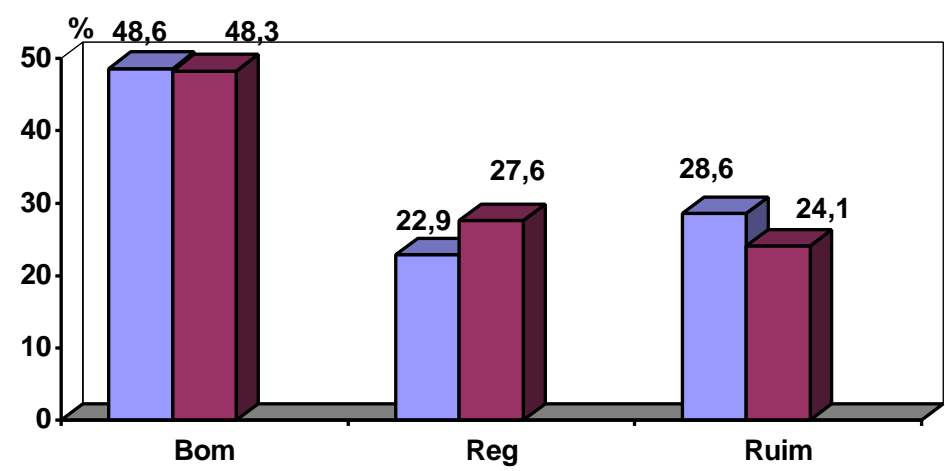

口Coronariopatas

$\square$ Controle

No grupo das coronariopatas $94 \%$ tinham filhos e no controle $78 \%$, resultando numa diferença significativa $(p=0,012)$.

A avaliação da qualidade do relacionamento com os filhos foi predominantemente boa e sem diferença estatística entre os dois grupos (Figura 4).

Figura 4 - Distribuição segundo a qualidade de relacionamento com os filhos.

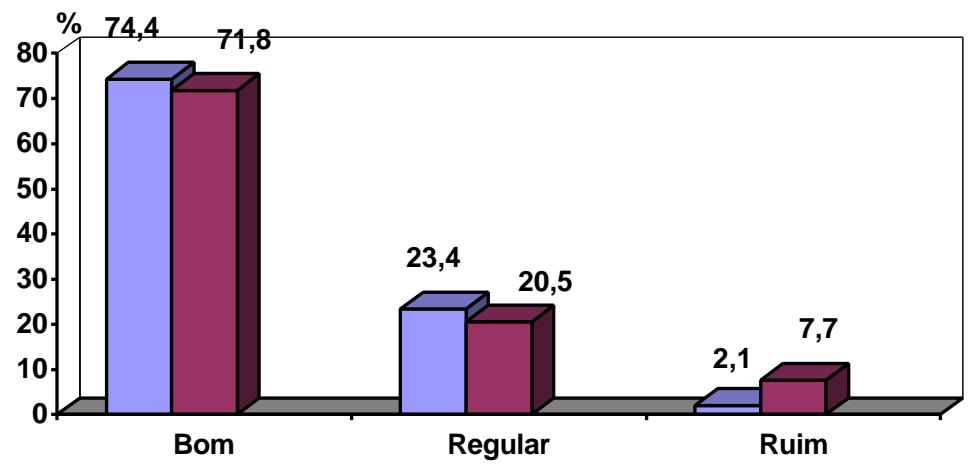


Com os demais membros da família (pais, sogros, cunhados, etc.) no grupo das coronariopatas $74 \%$ apresentavam bom relacionamento e $26 \%$ regular, e no grupo controle, $82 \%$ tinham bom relacionamento, $10 \%$ regular e $8 \%$ ruim.

\section{Atividades domésticas e vida profissional}

A prevalência das atividades em casa foi semelhante entre os grupos, e exercida pela quase totalidade das mulheres. Apenas duas mulheres, uma de cada grupo, não realizavam as tarefas domésticas, a coronariopata por limitação física e a do grupo controle por possuir empregada doméstica. Contudo ao analisarmos as atividades profissionais desenvolvidas fora de casa houve diferença entre os grupos. Assim, 14\% das coronariopatas contra $52 \%$ das mulheres do grupo controle mantinham atividade profissional fora do lar ( $p$ $=0,001)$. As atividades remuneradas exercidas no próprio lar foram semelhantes, $14 \%$ e $22 \%$ respectivamente nos grupos das coronariopatas e controles (Tabela 2). 
Tabela 2 - Distribuição das pacientes segundo atividade desenvolvida.

\begin{tabular}{lccccc}
\hline \multicolumn{1}{c}{ Atividade } & \multicolumn{2}{c}{ Coronariopatas } & \multicolumn{2}{c}{ Controle } & Total \\
\hline & № & $\%$ & № & $\%$ & № \\
Trabalhos de casa & 49 & $98 \%$ & 49 & $98 \%$ & 98 \\
Atividade comércio em casa & 7 & $14 \%$ & 11 & $22 \%$ & 18 \\
Atividade prof. fora do lar & 7 & $14 \%$ & 26 & $52 \%$ & $33^{*}$ \\
\hline
\end{tabular}

* $(p=0,001)$

\section{Atividades sociais, de lazer e esportivas}

Em relação a essas atividades, os resultados foram semelhantes nos dois grupos (Tabela 3).

Tabela 3 - Distribuição das pacientes segundo atividades de lazer e esporte.

\begin{tabular}{lcccccccccccc}
\hline Atividade & \multicolumn{1}{c}{ Coronariopatas } & \multicolumn{4}{c}{ Controles } \\
\hline & Frequente & \multicolumn{1}{c}{ Raramente } & \multicolumn{1}{c}{ Nunca } & \multicolumn{1}{c}{ Frequente } & \multicolumn{2}{c}{ Raramente } & \multicolumn{2}{c}{ Nunca } \\
& № & $\%$ & № & $\%$ & № & $\%$ & № & $\%$ & № & $\%$ & № & $\%$ \\
Lazer & 25 & 50 & 23 & 46 & 2 & 4 & 27 & 54 & 23 & 46 & - & - \\
Festas & 10 & 20 & 26 & 52 & 14 & 28 & 14 & 28 & 22 & 44 & 14 & 28 \\
Viagens & 11 & 22 & 16 & 32 & 23 & 46 & 14 & 28 & 19 & 38 & 17 & 34 \\
Esportes & 1 & 2 & 1 & 2 & 48 & 96 & 2 & 4 & 1 & 2 & 47 & 94 \\
Andar & 23 & 46 & 22 & 44 & 5 & 10 & 37 & 74 & 13 & 26 & - & - \\
Correr & - & - & - & - & 50 & 100 & - & - & 2 & 4 & 48 & 96 \\
\hline
\end{tabular}

\section{Aspectos emocionais}

Percebe-se que todas as queixas emocionais foram relatadas por mais da metade das mulheres coronariopatas, com menor percentual nas saudáveis. Ocorreu diferença significativa em relação ao choro fácil $(p=0,04)$ e à sensação de cansaço e esgotamento $(p=0,04)$ (Tabela 4). 
Tabela 4 - Distribuição das pacientes segundo aspectos emocionais.

\begin{tabular}{lccccc}
\hline \multicolumn{1}{c}{ Aspecto Emocional } & \multicolumn{2}{c}{ Coronariopatas } & \multicolumn{2}{c}{ Controles } & Total \\
\hline & № & $\%$ & № & $\%$ & № \\
Tristeza & 29 & 58 & 20 & 40 & 49 \\
Chora facilmente & 32 & 64 & 22 & 44 & 54 \\
Nervosa & 35 & 70 & 23 & 46 & 58 \\
Dificuldade de concentração & 30 & 60 & 21 & 42 & 51 \\
Insatisfação com a vida & 25 & 50 & 16 & 32 & 41 \\
Ansiedade & 35 & 70 & 28 & 56 & 63 \\
Alteração de memória & 34 & 68 & 32 & 64 & 66 \\
Irritabilidade & 29 & 58 & 23 & 46 & 52 \\
Desejo de isolamento & 32 & 64 & 25 & 50 & 57 \\
Cansaço e esgotamento & 35 & 70 & 25 & 50 & 60 \\
\hline
\end{tabular}

\section{Auto-imagem}

Apesar de $48 \%$ das coronariopatas terem percebido alteração na aparência ou viço da pele, $52 \%$ estavam satisfeitas com a aparência atual.

O mesmo ocorreu com as mulheres do grupo controle, onde $60 \%$ estavam satisfeitas com a aparência atual e o mesmo percentual referiu alterações negativas na aparência e viço da pele.

Em relação ao sentimento de preservação das capacidades, isto é, sentir-se tão capaz quanto era anos atrás, no grupo das coronariopatas $52 \%$ consideraram manter suas capacidades e $48 \%$ já não se sentem tão capazes. No grupo controle $76 \%$ acham que preservam suas capacidades e $24 \%$ sentem piora. Nesse aspecto há uma diferença significante $(p=0,03)$.

No que se refere a alteração de peso; a maioria, tanto entre as coronariopatas, quanto entre as controles, referiram aumento do mesmo. No grupo das 
coronariopatas a porcentagem de diminuição do peso foi maior, contudo sem diferença estatisticamente significante (Figura 5).

Figura 5 - Distribuição das pacientes segundo alteração de peso.

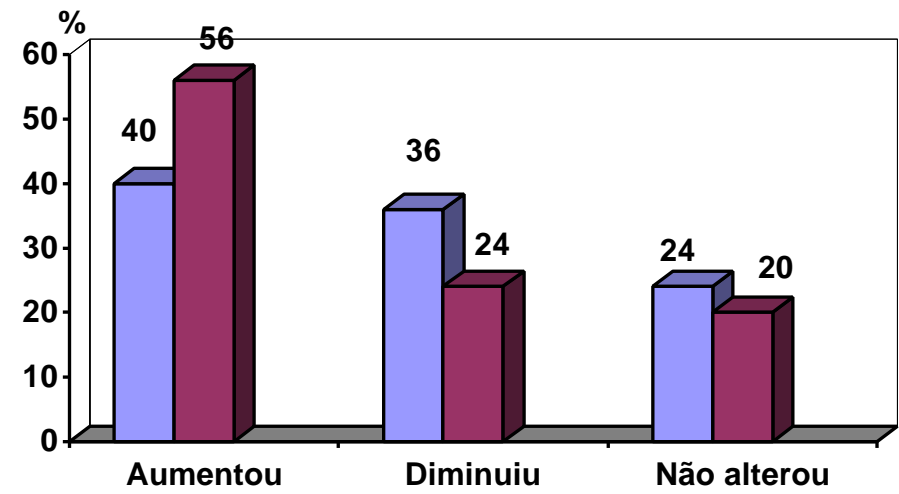

$\square$ Coronariopatas $\square$ Controle

Quando questionadas a respeito da percepção de outras pessoas sobre a aparência física, 46\% e 68\%, respectivamente nos grupos de coronariopatas e controles, relataram a percepção de piora $(p=0,04)$ (Figura 6).

Figura 6 - Distribuição das pacientes segundo percepção dos outros.

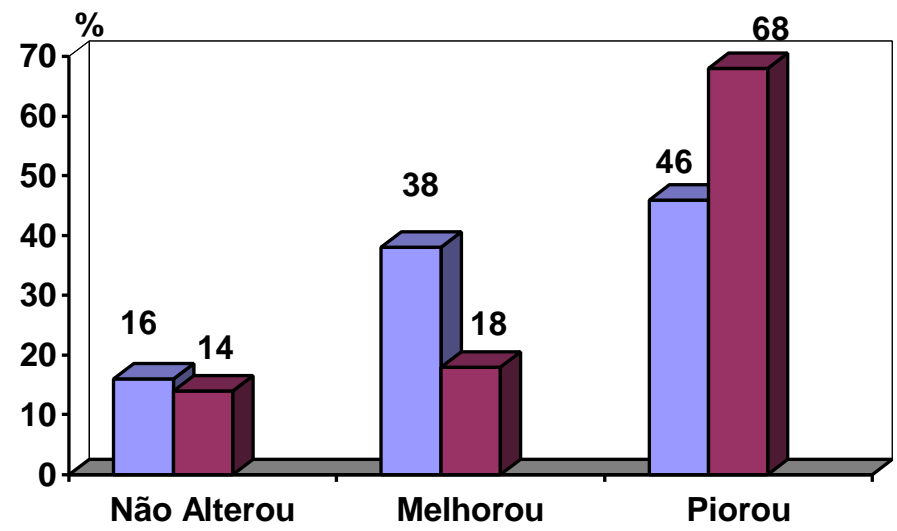




\section{Saúde}

No grupo das coronariopatas $100 \%$ tinham problema de saúde, enquanto no grupo controle, $42 \%$ referem algum problema de saúde $(p<0,0001)$.

\section{Uso de medicação}

Entre as coronariopatas $100 \%$ faziam uso de algum tipo de medicação e no grupo controle $24 \%(p<0,0001)$. A diferença deveu-se ao uso de medicações relacionadas a coronariopatia. O uso de antiinflamatórios foi semelhante nos dois grupos. Quanto ao tipo de medicação utilizada, temos: (Tabela 5)

Tabela 5 - Distribuição das pacientes segundo uso de medicação.

\begin{tabular}{lcccc}
\hline Tipo de Medicação & \multicolumn{2}{c}{ Coronariopatas } & \multicolumn{2}{c}{ Controles } \\
\hline & № & $\%$ & № & $\%$ \\
Betabloqueador & 31 & $62^{*}$ & - & - \\
Antagonista de Cálcio & 14 & $28^{*}$ & - & - \\
Nitrato & 27 & $54^{*}$ & - & - \\
Diurético & 20 & $40^{*}$ & - & - \\
Hipoglicemiante & 20 & $40^{*}$ & - & - \\
Insulina & 5 & $10^{*}$ & - & - \\
Anti- ECA & 28 & $56^{*}$ & - & - \\
Anti-inflamatório & 2 & 4 & 3 & 6 \\
Diazepínicos & 6 & 12 & - & - \\
Anti-depresssivo & - & - & 1 & 2 \\
Anti-histamínico & - & - & 2 & 4 \\
Cálcio & - & - & 4 & 8 \\
Broncodilatador & - & - & 2 & 4 \\
\hline
\end{tabular}

- $\mathrm{p}<0,0001$

\section{Sintomas}

Percentual de74\% das coronariopatas referiram apresentar algum sintoma, enquanto no grupo controle $26 \%$ queixaram-se de sintomas, $(p<0,001)$. O 
sintoma de dor osteoarticular esteve presente de modo semelhante nos dois grupos. Os sintomas citados foram: (Tabela 6)

Tabela 6 - Distribuição das pacientes segundo sintomas físicos.

\begin{tabular}{lcccc}
\hline \multicolumn{1}{c}{ Sintoma } & \multicolumn{2}{c}{ Coronariopatas } & \multicolumn{2}{c}{ Controles } \\
\hline Cansaço & № & $\%$ & № & $\%$ \\
Dor Precordial & 22 & $44^{*}$ & - & - \\
Dor Osteoarticular & 11 & $22^{*}$ & - & - \\
Prurido no Corpo & 9 & 18 & 9 & 18 \\
Chiado no Peito & - & - & 1 & 2 \\
Formigamento nas mãos & - & - & 1 & 2 \\
Dor nas Pernas & - & - & 1 & 2 \\
\hline
\end{tabular}

${ }^{*} p<0,001$

\section{Cirurgias}

Entre as pacientes coronariopatas $30 \%$ já haviam sofrido cirurgia de revascularização do miocárdio. Em relação às cirurgias obstétricas, ginecológicas, da mama e de varizes não houve diferença entre os dois grupos. Quanto aos tipos de cirurgia, temos: (Tabela 7) 
Tabela 7 - Distribuição das pacientes segundo tipo de cirurgia realizada.

\begin{tabular}{lcccc}
\hline Tipo de cirurgia & \multicolumn{2}{c}{ Coronariopatas } & \multicolumn{2}{c}{ Controles } \\
\hline & № & $\%$ & № & $\%$ \\
Revascularização miocárdio & 15 & $30^{*}$ & - & - \\
Obstétricas & 9 & 18 & 13 & 26 \\
Ginecológicas & 14 & 28 & 12 & 24 \\
Mama & 4 & 8 & 4 & 8 \\
Varizes & 3 & 6 & 3 & 6 \\
Outras & 16 & 32 & 19 & 38 \\
\hline
\end{tabular}

${ }^{*} p<0,001$

\section{Sintomas ligados ao climatério}

Não houve diferença significativa entre os dois grupos em qualquer dos sintomas do climatério (Tabela 8).

Tabela 8 - Distribuição das pacientes segundo sintomas físicos de climatério.

\begin{tabular}{lccccc}
\hline Sintomas & \multicolumn{2}{c}{ Coronariopatas } & \multicolumn{2}{c}{ Controles } & Total \\
\hline & № & $\%$ & № & $\%$ & № \\
Ondas de Calor & 37 & 74 & 28 & 56 & 65 \\
Transpiração Excessiva & 18 & 36 & 14 & 28 & 32 \\
Suores Noturnos & 18 & 36 & 20 & 40 & 38 \\
Palpitação & 18 & 36 & 12 & 24 & 30 \\
Dificuldade para Dormir & 27 & 54 & 22 & 44 & 49 \\
Lombalgia & 31 & 62 & 24 & 48 & 55 \\
Incontinência urinária & 21 & 42 & 13 & 26 & 34 \\
\hline
\end{tabular}




\section{Vida Sexual}

No grupo das coronariopatas $60 \%$ referem ter vida sexual e no controle $46 \%$.

Entre as mulheres que têm vida sexual ativa, verificou-se importante queixa de diminuição do desejo (Figura 7).

Figura 7 - Distribuição das pacientes segundo alterações no desejo sexual.

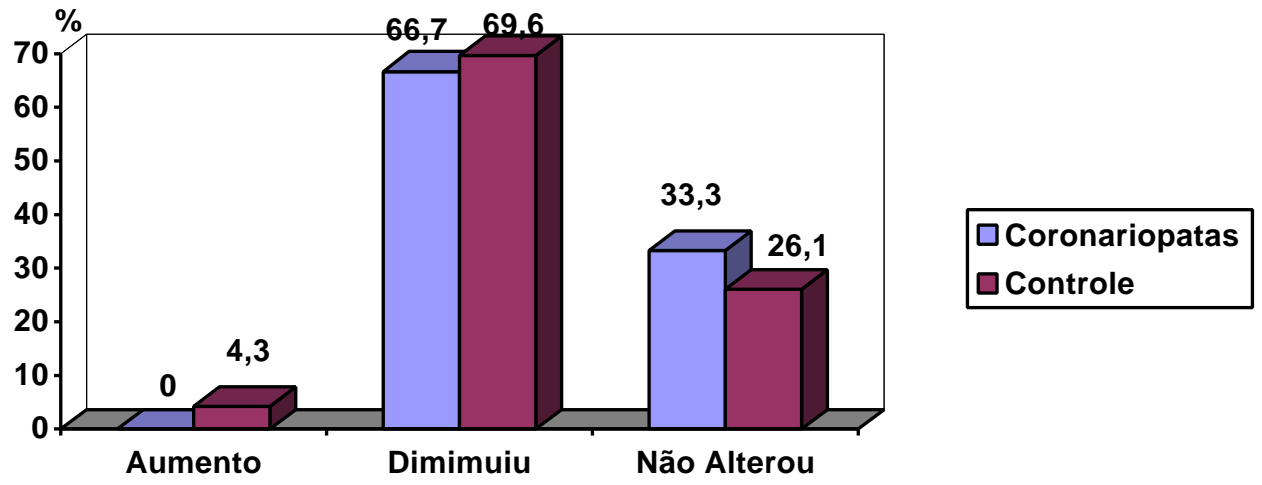

Em relação à satisfação com a vida sexual, 36,66\% e 43,47\% respectivamente nos grupos de coronariopatas e controles, relataram satisfação com a freqüência e qualidade das relações sexuais. No grupo das coronariopatas, $56,66 \%$ consideram que o parceiro está satisfeito com a vida sexual do casal e no grupo controle $60,86 \%$.

A queixa de pouca lubrificação vaginal foi relatada por $46,66 \%$ das coronariopatas e por $60,86 \%$ do grupo controle, não apresentando diferença estatística $(p=0,45)$. 
Apesar da dispareunia (dor durante relação sexual) ser três vezes mais frequente nas mulheres do grupo controle $30,4 \%$, contra $10 \%$ nas coronariopatas, essa diferença não alcançou significância estatística $(p=0,08)$.

\section{Percepção da qualidade de vida}

Apesar da frequencia de auto-avaliação da qualidade de vida como boa ser maior no grupo controle (52\%), contra $32 \%$ no grupo das coronariopatas, essa diferença não foi estisticamente significante $(p=0,07)$ (Figura 8).

Figura 8 - Distribuição das pacientes segundo auto-avaliação da qualidade de vida

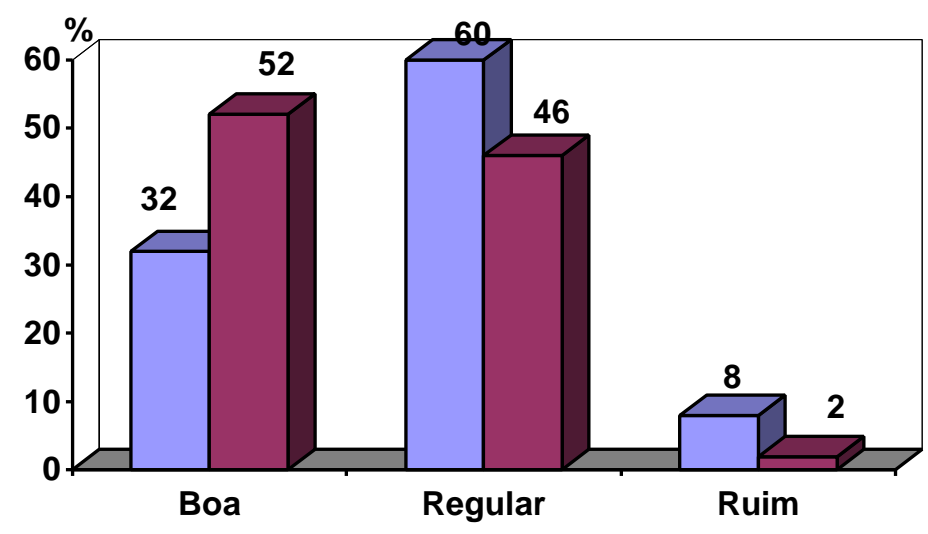

$\square$ Coronariopatas

$\square$ Controle

Os motivos apontados pelas pacientes como justificativa para classificarem a qualidade de vida como " Boa ", estão apresentados na tabela 9. 
Tabela 9 - Motivos citados para classificação da qualidade de vida como "BOA".

\begin{tabular}{|c|c|c|c|c|c|}
\hline \multirow[t]{2}{*}{ Motivos } & \multicolumn{2}{|c|}{ Coronariopatas } & \multicolumn{2}{|c|}{ Controles } & \multirow[t]{2}{*}{ Total } \\
\hline & № & $\%$ & № & $\%$ & \\
\hline Relação familiar satisfatória & 7 & 14 & 6 & 12 & 13 \\
\hline Situação econômica estável & 4 & 8 & 5 & 10 & 9 \\
\hline Estar com saúde & 3 & 6 & 2 & 4 & 5 \\
\hline Trabalho satisfatório & 2 & 4 & 7 & 14 & 9 \\
\hline Aceitação passiva realidade & 2 & 4 & 8 & 16 & 10 \\
\hline Equilíbrio emocional & 1 & 2 & 2 & 4 & 3 \\
\hline
\end{tabular}

A classificação da qualidade de vida como "Regular" decorreu, em sua maior parte de problemas na relação familiar (Tabela 10).

Tabela 10 - Motivos citados para classificação da qualidade de vida como "REGULAR".

\begin{tabular}{|c|c|c|c|c|c|}
\hline \multirow[t]{2}{*}{ Motivos } & \multicolumn{2}{|c|}{ Coronariopatas } & \multicolumn{2}{|c|}{ Controles } & \multirow{2}{*}{$\begin{array}{c}\text { Total } \\
\text { № }\end{array}$} \\
\hline & № & $\%$ & № & $\%$ & \\
\hline Problemas relação familiar & 21 & 42 & 10 & 20 & 31 \\
\hline Problemas de Saúde & 6 & 12 & - & - & 6 \\
\hline $\begin{array}{l}\text { Situação } \\
\text { precária }\end{array}$ & 6 & 12 & 5 & 10 & 11 \\
\hline Problemas Emocionais & 4 & 8 & 2 & 4 & 6 \\
\hline Excesso de Trabalho & - & - & 1 & 2 & 1 \\
\hline Desemprego & - & - & 1 & 2 & 1 \\
\hline Perda de Filho & - & - & 1 & 2 & 1 \\
\hline Não ter filhos & - & - & 1 & 2 & 1 \\
\hline
\end{tabular}

A classificação da qualidade de vida com "Ruim" foi motivada particularmente por problemas na relação familiar, no grupo das coronariopatas, e por aspectos emocionais no grupo controle (Tabela 11). 
Tabela 11 - Motivos citados para classificação da qualidade de vida como "RUIM".

\begin{tabular}{|c|c|c|c|c|c|}
\hline \multirow[t]{2}{*}{ Motivos } & \multicolumn{2}{|c|}{ Coronariopatas } & \multicolumn{2}{|c|}{ Controles } & \multirow{2}{*}{$\begin{array}{c}\text { Total } \\
\text { № }\end{array}$} \\
\hline & № & $\%$ & № & $\%$ & \\
\hline Problemas relação familiar & 3 & 6 & - & - & 3 \\
\hline Situação econômica ruim & 2 & 4 & - & - & 2 \\
\hline Problemas de Saúde & 1 & 2 & - & - & 1 \\
\hline Aspectos emocionais & - & - & 1 & 2 & 1 \\
\hline
\end{tabular}

As justificativas podiam envolver mais de um aspecto.

\section{Planos para o futuro}

Significativo percentual $46 \%$ e $40 \%$, respectivamente nos grupos de coronariopatas e controles, referiram não ter planos para o futuro.

Os planos para o futuro incluem amplo leque de opções que incluem questões referentes a saúde, aspectos econômicos, familiares, emocionais, perspectivas educacionais e de lazer (Tabela 12).

Tabela 12 - Planos para o futuro mais citados.

\begin{tabular}{|c|c|c|c|c|c|}
\hline \multirow{2}{*}{ Planos } & \multicolumn{2}{|c|}{ Coronariopatas } & \multicolumn{2}{|c|}{ Controles } & \multirow{2}{*}{$\begin{array}{c}\text { Total } \\
\text { № }\end{array}$} \\
\hline & № & $\%$ & № & $\%$ & \\
\hline Tratamento melhorar saúde & 7 & 14 & 3 & 6 & 10 \\
\hline Lazer, passeios e viagens & 5 & 10 & 6 & 12 & 11 \\
\hline Planos para vida dos filhos & 6 & 12 & 4 & 8 & 10 \\
\hline Trabalhar & 4 & 8 & 6 & 12 & 10 \\
\hline Ter casa própria & 3 & 5 & 5 & 10 & 8 \\
\hline Aposentadoria & 2 & 4 & 2 & 4 & 4 \\
\hline Mudança de residência & 2 & 4 & - & - & 2 \\
\hline Separação conjugal & 1 & 2 & 1 & 2 & 2 \\
\hline Ter um companheiro & 1 & 2 & 2 & 4 & 3 \\
\hline Voltar a estudar & - & - & 1 & 2 & 1 \\
\hline Mudar estilo de vida & - & - & 1 & 2 & 1 \\
\hline
\end{tabular}




\section{Como melhorar a vida}

No grupo das coronariopatas $20 \%$ não sabem o que poderiam fazer para melhorar a vida; $6 \%$ consideram que estão bem, não havendo necessidade de mudança e 4\% acham que não há mais condições de melhora.

No grupo controle, $30 \%$ não sabem como poderiam melhorar a vida e $6 \%$ consideram que estão bem.

As que consideram que podem fazer algo para melhorar a vida referem-se a:

(Tabela 13).

Tabela 13 - Aspectos citados como formas para melhorar a vida.

\begin{tabular}{|c|c|c|c|c|c|}
\hline \multirow[t]{2}{*}{ Como melhorar a vida } & \multicolumn{2}{|c|}{ Coronariopatas } & \multicolumn{2}{|c|}{ Controles } & \multirow{2}{*}{$\begin{array}{c}\text { Total } \\
\text { № }\end{array}$} \\
\hline & № & $\%$ & № & $\%$ & \\
\hline Trabalho/melhorar economia & 10 & 20 & 14 & 28 & 24 \\
\hline Atividades lazer/viagens & 8 & 16 & 3 & 6 & 11 \\
\hline Mudar estilo de vida & 8 & 16 & 6 & 12 & 14 \\
\hline Ter saúde & 6 & 12 & - & - & 6 \\
\hline Melhoria relações familiares & 3 & 6 & 3 & 6 & 6 \\
\hline Ampliar relacionamentos & - & - & 2 & 4 & 2 \\
\hline Reformar apartamento & - & - & 1 & 2 & 1 \\
\hline Trabalhar menos & - & - & 1 & 2 & 1 \\
\hline
\end{tabular}

$S F-36$

Houve diferença estatisticamente significante com melhores resultados no grupo controle quanto a capacidade funcional, aspectos físicos, estado geral da saúde, escore total dos componentes físicos, vitalidade e escore total dos componentes mentais. Não houve diferença entre os grupos quanto a dor, aspectos sociais, aspecto emocional e saúde mental (Tabela 14) e (Figura 9). 
Tabela 14 - Distribuição dos resultados obtidos no SF-36 (Mediana).

\begin{tabular}{lcc}
\hline Componentes do SF - 36 & Coronariopatas & Controles \\
\hline Capacidade Funcional & 50,50 & $84,00^{*}$ \\
Aspectos Físicos & 45,50 & $84,00^{*}$ \\
Dor & 62,38 & 70,98 \\
Estado Geral de Saúde & 59,10 & $87,22^{*}$ \\
Escore total comp. Físicos & 54,24 & $81,55^{*}$ \\
Vitalidade & 51,40 & $69,70^{*}$ \\
Aspectos Sociais & 60,75 & 72,75 \\
Aspecto Emocional & 69,95 & 77,97 \\
Saúde Mental & 52,20 & 61,12 \\
Escore total comp. Mentais & 58,57 & 70,38 **
\end{tabular}
$p<0,0001 ;{ }^{* *} p=0,0278$

Figura 9 - Distribuição dos resultados obtidos no SF-36 ( Mediana )

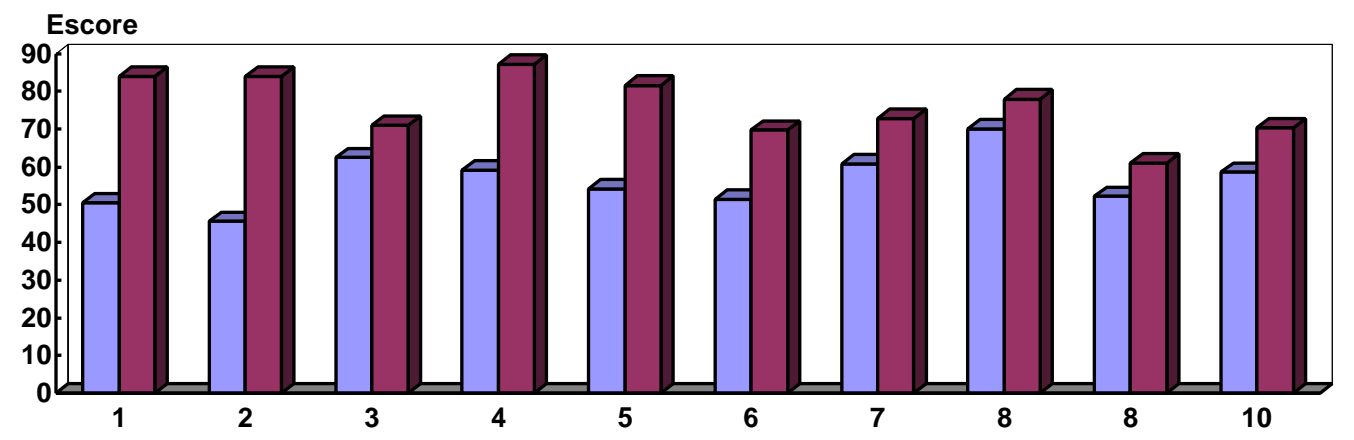

\begin{tabular}{l} 
1 Capacidade Funcional \\
\hline $\mathbf{2}$ Aspectos Físicos \\
\hline $\mathbf{3}$ Dor \\
\hline $\mathbf{4}$ Estado geral de Saúde \\
\hline $\mathbf{5}$ Componentes Físicos \\
\hline 6 Vitalidade \\
\hline $\mathbf{7}$ Aspectos Sociais \\
\hline $\mathbf{8}$ Aspecto emocional \\
\hline $\mathbf{9}$ Saúde Mental \\
\hline $\mathbf{1 0}$ Escore Total dos Componentes Mentais \\
\hline
\end{tabular}

$\checkmark$ Coronariopatas

$\checkmark$ Controle 


\section{DISCUSSÃO}

A doença cardiovascular é a causa mais importante de morte e incapacitação entre as mulheres após a menopausa nos Estados Unidos (SCHENCKGUSTATSSON, 1996). No Brasil, as taxas de mortalidade feminina por doença coronária, entre 45 e 65 anos, mostram-se maiores do que aquelas de países desenvolvidos (LOTUFO, 1996).

A prática clínica tem revelado importantes aspectos psicossociais que envolvem a cardiopatia e o climatério.

O presente estudo avaliou um aspecto psicossocial que é a qualidade de vida de mulheres coronariopatas após a menopausa e de mulheres não portadoras de doença (grupo controle), por meio de entrevista estruturada e da aplicação de um instrumento que mensura a qualidade de vida, o questionário genérico de avaliação de qualidade de vida (SF-36).

Quanto à metodologia empregada em nosso estudo ressalta-se que as entrevistas estruturadas mostraram-se abrangentes, permitindo que as pacientes expressassem claramente seus sentimentos relativos às diversas áreas da vida.

O SF-36, por ser um instrumento elaborado para pesquisar qualidade de vida na área de saúde, possibilitou a obtenção de dados objetivos sobre os componentes físicos e mentais, favorecendo a comparação dos dois grupos. 
Os dois grupos mostraram-se homogêneos em relação a época em que ocorreu a menopausa e nível sócio-econômico-cultural. Quanto à escolaridade constatou-se que $84 \%$ dos dois grupos cursaram $1^{\circ}$ grau, resultado similar ao da população feminina brasileira na mesma faixa etária no Estado de São Paulo (DATASUS, 1996).

O padrão sócio-econômico e as atividades profissionais também mostram-se semelhantes nos dois grupos estudados, devendo ser ressaltado a dupla jornada de trabalho das mulheres.

No grupo de coronariopatas constatou-se que a maioria (68\%) dedica-se exclusivamente aos afazeres domésticos. No grupo controle, $52 \%$ das mulheres, além das atividades domésticas, trabalham também fora do lar, diferentemente das coronariopatas em que apenas $14 \%$ vivem esta situação. Esta diferença pode ser explicada pelo estado físico, visto que a coronariopatia causa importantes sintomas como cansaço (44\%) e dor precordial (22\%) dificultando, dessa forma o engajamento em trabalhos fora de casa. Além do mais, como o grupo de coronariopatas é formado predominantemente por mulheres de baixa escolaridade, e como esta condição, na maioria das vezes, redunda no achado de trabalhos mais pesados, é possível que explique também o reduzido número de coronariopatas que trabalham fora de casa.

Ao se analisar os resultados do SF-36, no que tange aos componentes físicos (capacidade funcional, aspecto físico e estado geral de saúde), constatam-se diferenças significativas entre as coronariopatas e o grupo controle. Assim, as coronariopatas mostram-se muito mais limitadas em sua condição física. 
Entretanto, ao se avaliar o componente dor no SF-36 verifica-se que não há diferença significativa entre os grupos, apesar das coronariopatas terem mais dor precordial. As causas de maior interferência nas atividades do dia-dia nos dois grupos foram a dor lombar e limitação de movimentos, decorrente do comprometimento osteoarticular e provavelmente relacionado ao fator idade.

Diferentemente do físico, os componentes mentais do SF-36 (aspectos sociais, emocionais e saúde mental) não desvelaram diferenças significativas entre os dois grupos.

Conforme visto anteriormente, a coronariopatia exerce forte impacto sobre os componentes físicos, levando a diferenças significativas entre os dois grupos; entretanto, no que se refere aos componentes mentais, as dificuldades emocionais, sociais e de relações interpessoais não mostram diferenças tão acentuadas, embora na avaliação total do componente mental as coronariopatas mostrem-se em desvantagem.

Apesar da vitalidade ser parte integrante dos componentes mentais, ela pode também ter interferência do componente físico; por isso, os resultados mostraram um maior prejuízo entre as coronariopatas.

Em relação à realização de cirurgias, nosso estudo mostrou que $30 \%$ das coronariopatas submeteram-se a revascularização do miocárdio; quanto às cirurgias obstétricas, ginecológicas, de mama, varizes o resultado revelou-se semelhante nos dois grupos.

Os sintomas ligados ao climatério como ondas de calor, transpiração excessiva, suores noturnos, não apresentaram diferenças significativas entre os dois 
grupos; ressalta-se, no entanto, que as ondas de calor foram frequentes nos dois grupos, resultado que assemelha-se ao de HALBE (1995), em que 75\% a 85\% das mulheres são acometidas pelos fogachos, sendo geralmente desencadeados por quadros emocionais, e que podem alterar a rotina de vida. Do exposto parece claro que a menopausa associa-se a uma ampla gama de sintomas. A partir daí, surgem duas correntes de opinião. Uma considera a menopausa como uma fase de desenvolvimento normal, outra a define como uma endocrinopatia. Sob o ponto de vista de BERNSTEIN e LENHART (1993), a associação da menopausa ao processo de envelhecimento, a acontecimentos desenvolvimentais e ambientais, estimulou a criação de uma atmosfera de controvérsias na mente das mulheres e dos profissionais de saúde.

Cabe lembrar que o climatério tem uma evolução diferente para cada mulher, dependendo de suas características intrapsíquicas e contexto sócio-cultural, podendo assim, ser mais ou menos conflitante. É um período de vulnerabilidade que pode exacerbar condições psíquicas patológicas préexistentes, ou por outro lado ser vivido como momento de desenvolvimento e amadurecimento pessoal, abrindo-se perspectivas em direção ao futuro (MARRACCINI, 1999).

Nas entrevistas, ao se avaliar os aspectos emocionais tais como sentimentos de tristeza, choro fácil, insatisfação com a vida, ansiedade, irritabilidade e desejo de isolamento, não constatamos diferenças nos dois grupos estudados, apesar de ocorrerem em proporção mais elevada nas coronariopatas. 
Sensação de cansaço e esgotamento apresentam resultados significativamente maior entre as coronariopatas, apesar de 50\% das mulheres do grupo controle referirem a mesma queixa.

Nas investigações de SHERWIN (1993) observou-se que entre mulheres norte americanas que procuram atendimento médico na fase da menopausa, $79 \%$ apresentam sintomas físicos e 65\% referem variados graus de depressão, expressando a relevância dos sintomas psicológicos. Por isso, é imperioso que se avaliem as mulheres dentro de uma amplo contexto que deve incluir não só o médico, mas também o psico-sócio-cultural.

A psicanalista BENEDEK (1950), indicava há mais de cinco décadas, que a terapêutica com hormônios alivia os sintomas neurovegetativos, mas os conflitos emocionais não se resolvem sem psicoterapia adequada; para ela é fundamental a compreensão cuidadosa da personalidade e do que se passa com a paciente.

O relacionamento com o companheiro não teve diferenças entre os dois grupos, salientando, no entanto, que mais de $50 \%$ das mulheres revelaram relacionamento regular ou ruim nos dois grupos.

Ao se analisar o número de filhos constatam-se importantes diferenças entre os dois grupos; assim, 94\% das coronariopatas tem filhos contra $78 \%$ do grupo controle. Explica-se essa diferença pelo maior contigente de mulheres solteiras no grupo controle (14\%), contra $4 \%$ das coronariopatas.

A qualidade de relacionamento com os filhos foi avaliada de forma mais positiva pelas coronariopatas. Nesse sentido, é interessante observar que 
muitas destas mulheres perderam o interesse e a admiração pelo companheiro, resultando em uma relação menos afetiva. Assim, com a doença em curso e o inadequado relacionamento conjugal, nossos resultados mostram que as coronariopatas tornam-se mais dependentes dos filhos. Inúmeros foram os relatos que confirmam tal achado, tais como "sou cuidada pelos filhos " ou de " continuar vivendo por causa deles ".

Por outro lado, é importante considerar que a doença da mãe pode gerar atitudes superprotetoras dos filhos, talvez desencadeadas por sentimentos de culpa por elas terem sempre exercido o papel de cuidadoras e agora encontrarem-se debilitadas fisicamente.

"Tenho minha família ligada a mim, todos se preocupam comigo. Criei todos sozinha e agora tenho todos à minha volta. Quando divorciei enfrentei muitos problemas, foi uma decisão muito difícil, a sociedade tem preconceito, até hoje sinto isso. Trabalhava muito para poder criar meus filhos, tinha dois empregos, fazia todo o serviço da casa. Sempre digo para os meus filhos: Vocês são a minha vida". JLS - 62 anos (A)

O relacionamento com os demais membros da família (pais, sogros, cunhados, etc.) não mostrou diferenças entre os dois grupos estudados.

As atividades sociais e de lazer também apontaram resultados semelhantes entre os dois grupos. A participação em festas e viagens ocorrem com baixa 
freqüência e as justificativas relacionam-se, em sua maioria, às dificuldades econômicas. Ao se referirem a passeios, geralmente citam visitas a parentes e filhos.

O envolvimento em atividades esportivas demonstrou ser mínimo nos dois grupos, independente das condições físicas. A prática esportiva parece não fazer parte dos hábitos destas mulheres

Em relação a auto-imagem, incluindo a satisfação com a aparência atual e a percepção das alterações no viço da pele, os resultados foram semelhantes nos dois grupos, embora o depoimento de algumas mulheres reforcem a percepção de que alterações corporais são conceituadas como muito negativas.

"Sempre fui vaidosa, gosto de andar arrumada, mas estou velha e acabada, minha pele murchou, tenho vontade de fazer plástica mas isso é coisa para rico". MPS - 55 anos $(A)$

"Tenho até vergonha de encontrar pessoas conhecidas, que me conheceram quando era moça, fiquei muito feia". APO - 56 anos (B)

No tocante ao sentimento de preservação das capacidades física e funcional ocorreu significativa diferença entre os grupos; assim no grupo controle $76 \%$ consideraram preservar ambas as capacidades; esse resultado é explicado pela manutenção da atividade profissional, graças à condição física adequada 
para o trabalho, ou seja, não se deparam com limites físicos na execução de atividades da vida diária. Para as coronariopatas estes limites da capacidade física e funcional representam grande perda.

"Você sabe, uma pessoa enfartada não é a mesma coisa. Não consigo arrumar um trabalho leve para ter dinheiro para comprar pelo menos meus remédios". $T M 61-\operatorname{anos}(A)$

No que se refere a alterações de peso embora as diferenças não sejam significativas, as coronariopatas relatam maior diminuição de peso. $O$ emagrecimento pode estar ligado às dietas restritivas para hipertensão e diabetes, além do que é enfatizado constantemente pelo cardiologista a necessidade de controle do peso. Observa-se que o emagrecimento acaba influenciando na auto-estima destas mulheres. Quando questionadas a respeito da percepção dos outros sobre sua aparência física, 38\% das coronariopatas referem que os outros as percebem melhor e justificam pelo emagrecimento.

A menopausa associa-se a modificações na composição corpórea, independente de alterações no peso; são características a perda rápida do conteúdo mineral ósseo, o declínio da massa muscular e o aumento da massa gordurosa. Na mulher, antes da menopausa, o tecido adiposo predomina habitualmente na região glútea e femoral, diferentemente daquela após a 
menopausa, em que ocorre um predomínio da gordura abdominal (DAWSON E HARRIS, 1992).

As mudanças corpóreas que começam a ocorrer na meia-idade normalmente provocam uma auto-estranheza inicial. Depois, espera-se que a mulher incorpore essas mudanças e reorganize sua nova identidade, embora isso não ocorra em algumas pessoas. (HALBE, 1995).

Nosso estudo revela elevada porcentagem de mulheres com diminuição do desejo sexual; entre as coronariopatas $66,66 \%$ e no grupo controle $69,56 \%$.

"Só faço por obrigação de vez em quando. Tudo me irrita, não tenho vontade e ele fica bravo. Sempre fui mulher para ele, mas agora não dá mais. De vez em quando fico com pena dele e cedo, mas não gosto, faço forçada". LCS - 59 $\operatorname{anos}(A)$

"Desde jovem sempre tive dificuldade de ter prazer, agora aos 53 anos só consigo ter relação a cada três semanas, meu marido não se conforma". NRO $53 \operatorname{anos}(B)$

"Nunca tive muito interesse, nunca fui fogosa, mas de um ano para cá não posso que ele me encoste. Ele é compreensivo, mas não agüento que ele me toque. Não temos relação há um ano, mas ele parece que não liga". NZHC 51 $\operatorname{anos}(B)$ 
As transformações biológicas, sociais, psicológicas e interpessoais que ocorrem conjuntamente no climatério, promovem relevante papel na determinação da função sexual nesta etapa da vida. Embora o interesse e a satisfação sexuais conservem-se na menopausa, há mulheres que vivenciam um declínio ou suspensão dos mesmos (FEBRASGO, 1995).

Em relação à qualidade e frequencia da vida sexual somente $36,66 \%$ das coronariopatas referem satisfação, e 43,74\% do grupo controle.

A sexualidade no climatério é influenciada por diversos fatores psicossociais, destacando-se o relacionamento afetivo com o parceiro, experiências prévias, além de influências sociais e culturais. A insatisfação com a sexualidade pode surgir como subproduto da interação deficiente do casal e mais de $50 \%$ das mulheres, em ambos os grupos, consideram o relacionamento com 0 companheiro regular e ruim.

"Tenho relacionamento sexual só raramente, quando não tem amor, carinho e afeto, não dá". IPS - 63 anos (A)

"Só de vez em quando, tenho problemas com meu marido, ele se preocupa mais com a família dele do que comigo. Sinto mágoa dele, é difícil me concentrar". MOS - 61 anos (B) 
A auto-estima afetada negativamente, pode levar essas mulheres a se considerarem menos atraentes e desejáveis e, em decorrência, tornam-se inseguras, prejudicando a exercício da sexualidade.

"Há três anos não tenho relações, estou muito gorda, pareço um barril, tenho vergonha do meu corpo. Também estou me achando inferior ao meu marido. Ele lê muito e ficou instruído, parece que tem faculdade e eu me acho ignorante. Ele me leva em todos os lugares quando tem alguma festa, mas nunca me elogia, mesmo quando eu me arrumo. Está certo que em gorda nada fica bem, mas ele poderia mentir para me agradar". MAO - 60 anos (A)

"Estou muito gorda, sei que tem gente que é gorda e encara isso numa boa, mas não consigo me imaginar transando com esse corpo". HAN - 55 anos (B)

A queixa de diminuição da lubrificação vaginal aparece em $46,66 \%$ das coronariopatas e em 60,86\% do grupo controle. Segundo LAURITZEN (1983), tal redução afeta o prazer e o desejo sexual, porém apenas a dispareunia, que neste estudo foi apontada por $10 \%$ das coronariopatas e $30,43 \%$ do grupo controle, está associada à redução da freqüência de relações sexuais. Apenas uma paciente atribuiu os sintomas da DIC como impedimento para o exercício da sexualidade. A coronariopatia não foi o principal fator na qualidade 
da vida sexual, diferentemente do componente afetivo dos relacionamentos conjugais que mostrou ser o preponderante nas dificuldades observadas na esfera sexual.

Além disto, a literatura denota que a disfunção sexual atinge 25 a 35\% das mulheres entre 35 e 39 anos e 51 a 75\% entre os 60/65 anos (OSBORN et al, 1988; PRIEST and CRISP, 1972; PFEIFFER et al, 1972); nunca é demais recordar que disfunção sexual constitui termo genérico, representado por alterações do desejo sexual, da excitação e do orgasmo, podendo também incluir as queixas sexuais dolorosas.

A auto-avaliação sobre a qualidade de vida revelou entre as coronariopatas o predomínio de uma avaliação regular (60\%) e no grupo controle uma avaliação boa (52\%). Satisfação no trabalho, bom relacionamento familiar e estabilidade econômica, são os fatores que mais pesam na avaliação das mulheres do grupo controle para classificarem a qualidade de vida como boa.

"Minha aposentadoria é pequena, mas vivo bem. Minha casa tem de tudo, parece casa de rico. Tenho duas casas, numa eu moro, a outra alugo. As contas eu pago tudo em dia, posso dormir sossegada. Mas ainda quero montar um negócio, vender churrasquinho, coisas para comer, estou tentando convencer meu marido". TRM - 58 anos (B) 
No relato abaixo observa-se muitas vezes que a avaliação vem envolvida por uma aceitação passiva da realidade.

"Acho que minha vida é boa. Tenho muita preocupação com os filhos, mas tenho de tudo em casa, trabalho, não falta nada. Meu marido está muito nervoso, mas fica mais no sítio do que aqui em São Paulo. Estou casada há 28 anos, já acostumei com ele e ele gosta muito dos filhos". MJSB - 50 anos (B)

Entre as coronariopatas a auto-avaliação da qualidade de vida como regular deve-se, na maioria das vezes, às dificuldades de relacionamento familiar, seguido dos problemas de saúde e da situação econômica precária.

"Minha vida é regular, meu marido trabalha fazendo bicos e minha filha ajuda nas despesas. Quando não sinto nada tenho disposição para trabalhar, mas quase sempre me sinto cansada. Depois do infarto não tenho vontade de nada, nem de passear. Só penso que vou morrer rápido". CSS - 55 anos (A)

Em relação aos planos para o futuro chama atenção a porcentagem de mulheres que não estabelecem planos para suas vidas, $46 \%$ entre as coronariopatas e $40 \%$ no grupo controle.

"O meu futuro é este, estou velha, vai ser do jeito que está. Há mais de 30 anos é a mesma rotina, acho que não vai mudar ". PRB - 56 anos $(A)$. 
"Entrego na mão de Deus, até aqui ele me ajudou. O amanhã não me pertence, pertence a Deus". MDM - 55 anos (B)

Constata-se, ainda, referências sobre planos para a vida dos filhos e não para si.

"Tento a sorte na loto, minhas duas filhas não tem casa. Se Deus permitir quero ver se ganho para comprar casa para elas". MAS - 61 anos (A)

"Não penso mais em mim. Gostaria de ajudar minha filha e meus netos para terem vida melhor". MIR - 59 anos (B)

Entre as coronariopatas o plano para futuro que aparece com maior destaque é o envolvimento no tratamento para melhorar a doença, o que reforça que os problemas de saúde representam o grande fator de interferência na qualidade de vida. Seguem-se, os planos de lazer, passeio, viagens e trabalho.

"O que eu espero... só tratar da doença e ter um pouco de saúde para passear um pouco". MLTA - 60 anos $(A)$ 
No grupo controle os planos predominantes são os que envolvem lazer, passeio, viagens, trabalhar e ter casa própria.

"Eu estudava, mas casei e parei os estudos. Fiquei vinte anos só cuidando da casa e dos filhos. Daí resolvi voltar a estudar, me formei e estou lecionando há dois anos. Meu plano é conseguir lecionar em escola particular porque paga melhor para poder viajar. Meu sonho sempre foi conhecer a Grécia". LMO - 52 $\operatorname{anos}(B)$

Quando questionadas sobre o que poderiam fazer para melhorar a vida observam-se atitudes depressiva, passivas, com pouco envolvimento com o próprio destino; entre as coronariopatas, $20 \%$ não sabem o que poderiam fazer para melhorar a vida, $6 \%$ consideram que estão bem assim e $4 \%$ apresentam perspectivas sombrias, ou seja, admitem que não há mais condições de melhora.

"Acho que minha vida não melhora mais. Estou velha, não tenho mais ânimo, acho que não dá mais não. Tenho medo de morrer e deixar minhas filhas". ISP $51 \operatorname{anos}(A)$

No grupo controle $30 \%$ também não sabem como poderiam melhorar a vida e $6 \%$ consideram que estão bem. 
"Não sou de muitas ilusões, estou satisfeita com o que tenho". MBF 49 $\operatorname{anos}(B)$

Trabalhar para melhorar a situação econômica aparece como fator principal nos dois grupos. Para as coronariopatas ter atividades de lazer e viagens também é bastante citado, bem como mudar o estilo de vida no sentido de ter hábitos mais saudáveis. Ter saúde para poder melhorar a vida aparece apenas entre as coronariopatas.

O conteúdo da fala das mulheres, em ambos os grupos, deixa transparecer com freqüência aspectos depressivos. A sintomatologia depressiva é altamente prevalente em indivíduos com mais de 50 anos, sendo que uma série de fatores biológicos, psicológicos e sociais contribui para torná-los mais vulneráveis. No caso da mulher, em particular, existe ainda outro fator que pode facilitar o aparecimento de sintomas depressivos: é a flutuação dos níveis de estrogênio na perimenopausa, ou seja quatro anos antes de se instalar a menopausa. É, também, importante considerar que esta fase de vida associase a uma série de eventos que podem contribuir para precipitar um quadro depressivo: morte de entes queridos, separação, mudança de papel social e, principalmente, no caso das coronariopatas, o surgimento da doença, o convívio com limites físicos e com o tratamento.

ALMEIDA e FRÁGUAS JR. (1996) referem que há três possíveis formas de associação entre depressão e doença cardiovascular: a depressão pode ser 
um fator de risco para o desenvolvimento de doença cardiovascular; as doenças cardiovasculares podem facilitar o aparecimento de sintomatologia depressiva e a doença cardiovascular não se associa com a depressão, mas pode correlacionar-se com fatores de risco comuns a ambas as doenças.

"A doença deixa a gente triste, quando fiquei doente, fiquei triste, achei que ia morrer. Estava deprimida, não via solução, queria dar descanso para os outros, tinha medo de dar trabalho". MSC - 59 anos (A)

É importante salientar que em nosso estudo muitas mulheres demonstraram através de seus relatos não terem um significado para a vida. Diversos estudos tem reconhecido a importância de um significado para a existência, a fim de se obter satisfação pessoal. Significado pessoal tem recebido definições envolvendo componentes de natureza cognitiva, motivacional e afetiva. Nesse sentido WONG (1989) elaborou uma definição síntese que engloba diversos componentes: " significado pessoal é um sistema construído individualmente, isto é, fundamentado em valores e capaz de dotar a vida de satisfação pessoal ".

Há mulheres que vivenciam de forma criativa seu desenrolar pela vida, encontrando sempre um novo sentido para crescerem, desenvolverem e contribuírem com o ambiente que as cerca; há, também, aquelas em que o 
envolvimento pragmático com tarefas cotidianas pode levar a um esvaziamento do espaço de viver imaginativo.

A mulher que entra em crise na meia-idade pode estar em busca de recapturar o sentimento de significado proveniente da vida criativa. WINNICOTT (1989), relata que o sintoma de uma vida não criativa é o sentimento de futilidade, de que nada importa.

Nos últimos anos os gerontólogos têm voltado sua atenção para o estudo do envelhecimento bem sucedido; embora não se tenha chegado ainda a um consenso sobre este conceito, admite-se que ele deveria incluir adequada saúde física, bem estar psicológico e competência de adaptação (WONG, 1989). 


\section{CONCLUSÕES}

- A coronariopatia interfere na qualidade de vida das mulheres após a menopausa, limitando a capacidade física e o desempenho das atividades da vida diária além de intensificar as dificuldades emocionais comuns nesse período.

- As mulheres sem coronariopatia apresentam-se mais ativas e com maior auto-estima no que se refere ao sentimento de preservação das capacidades.

- Tanto nas mulheres coronariopatas como nas sem coronariopatia ocorre significativa diminuição do desejo sexual na pós menopausa, bem como insatisfação com a frequencia e qualidade da vida sexual. Há tendência a apresentarem poucos planos para o futuro com metas e objetivos incertos e a presença frequente de conteúdos depressivos. 


\section{REFERÊNCIAS}

Abreu MAL. Compreensão holística da síndrome climatérica. Rio de Janeiro; 1992. [Tese de doutorado - Universidade Federal do Rio de Janeiro].

Aldrighi JM. Balanço risco/benefício da terapêutica de reposição hormonal: direções para o futuro. Rev Soc Cardiol Estado São Paulo 1996; 6: 734-7.

Almeida OP, Fráguas Jr R. Depressão e doença cardiovascular. Rev Soc Cardiol Estado São Paulo 1996; 6: 749 - 56.

Anda R, Williamson D, Jones D, Macera C, Eaker E, Glasman A, Marks J. Depressed affect, hopelessness and the risk of ischemic heart disease in a cohort of U.S. adults Epidemiology 1993; 4: 285- 94.

Appolinário JC. Terapia hormonal e os sintomas psíquicos na menopausa Parte 1 - Revisão de literatura. J Bras Psiquiatr 1992; 44: 169 - 76.

Atkinson R. Introduction to psychology. EUA Harcourt Brace \& Company Edition; 1993. 
Barr JT. The outcomes movement and health status measures. $\mathbf{J}$ Allied Health 1995; $24: 13-28$.

Biffi EFA. O fenômeno da menopausa: uma perspectiva de compreensão. Ribeirão Preto; 1991. [ Dissertação de mestrado - Enfermagem - Universidade de São Paulo ].

Benedek T. Climaterium: a developmental phase. Psychoanal Q 1950; 19: 127.

Benedek T, Rubinstein JR EC. Studies in psychosomatic medicine, psychosexual functions in women. New York: Ronald; 1952.

Bernstein AE, Lenhart AS. The psychodynamic treatment of women. American Psychiatric Press Inc; 1993.

Byyny RL, Speroff L. A clinical guide for the care of older women: primary and preventive care . 2nd ed. Baltimore: Williams \& Wilkins; 1996. The rectangularization of life; $1-19$.

Ciconelli RM. Tradução para o português e validação do Questionário Genérico de Avaliação de qualidade de vida “ Medical Outcomes study 36- 
Item Short -Form Health Survey (SF-36) São Paulo; 1997 [Tese de doutorado - Universidade Federal de São Paulo ].

Datasus. Ministério da Saúde. Informações de Saúde [on-line]. Disponível em: http:// www.datasus.gov.br/cgi/tabcgi.exe?ibge/estsp. [2000 jun 14]

Dawson-Hughes, Harris S. Regional changes in body composition by time of year in health post menopausal women. Am J Clin Nutr 1992; 56: 307 - 13.

Deutsch H. Psychology of women. New York: Grune \& Stratton; 1944.

Dennerstein L, Burrows GD. A review of studies of the psychological symptoms found at the menopause. Maturitas 1978; 1: 55-64.

Favarato MECS, Aldrighi JM, Favarato D, Mansur AP. Aspectos psicológicos das mulheres cardiopatas no climatério. Rev Bras Cardiol, 1999; 1 (2): 68 71.

[FEBRASGO] Federação Brasileira das Sociedades de Ginecologia e Obstetrícia Climatério: manual de orientação. 1995. 
Flanagan JC. Measurements of quality of life: current state of art. Arch Phys Med Reabil 1982; 63: $52-62$.

Fletcher AE. Evaluation of quality of life in clinical trials of cardiovascular disease. J Chron Dis 1987; 40: 557 - 66.

Friedman M, Rosenman $\mathrm{RH}$. Association of specific overt behavior pattern with blood and cardiovascular findings: blood cholesterol level, blood clotting time, incidence of arcus senilis, and clinical coronary artery disease. JAMA 1959; 169: 1286- 96.

Guyatt GH. A taxonomy of health status instruments. J Rheumatol 1995; 22: $1188-90$.

Guyatt GH, Naylor D, Juniper E, Heyland DK, Jaeschke R, Cook DJ. User's guides to the medical literature. XII How to use articles about health - related quality of life. JAMA 1997; 277: 1232 - 6.

Haines AP, Imeson JD, Meade TW. Phobic anxiety and ischemic heart disease. BMJ 1987; 295: 297- 9. 
Halbe AFP. Aspectos emocionais do climatério. In: Pinotti JA, Halbe HW, Hegg R. Menopausa. São Paulo: Rocca; 1995.

Holmes T, Rahe R. The social readjustment rating scale. J Psychosom Res 1967; 11: 213- 8 .

Kannel W. Menopause and risk of cardiovascular disease: the Framinghan Study. Ann Intern Med 1976; 85: 447- 52.

Katz JN, Larson MG, Phillips CB, Fossel AH, Liang MH. Comparative measurement sensitivity of short and longer health status instruments. Med Care 1992; 30: $917-25$.

Kawachi I, Sparrow D, Vokonas OS, Weiss ST. Symptoms of anxiety and risk of coronary heart disease: the normative aging study . Circulation 1994; 90 : 2225- 9 .

King KB. Psychologic and social aspects of cardiovascular disease Ann Behav Med 1997; 19: 264-70.

Kusnetzoff JC. A mulher sexualmente feliz. Rio de Janeiro: Nova Fronteira; 1988. 
Lamosa BWR. Psicologia aplicada à cardiologia. São Paulo: Fundo Editorial BYK; 1990.

Lauritzen C. Biology of female sexuality in old age. Z Gerontol 1983; 16: 1348.

Lotufo PA. Doenças cardiovasculares no Brasil: por que altas taxas de mortalidade? Rev Soc Cardiol Estado São Paulo 1996; 6: 667 - 71.

Marraccini EM. Mulher significados no meio da vida. São Paulo; 1999. [Dissertação de Mestrado - Psicologia - Pontifícia Universidade Católica de São Paulo].

Ministério da Saúde. Departamento de Assistência e Promoção à Saúde/coordenação Materno-Infantil. Assistência ao climatério. Brasília (DF); 1994.

Osborn M, Hawton K, Gath D. Sexual dysfunction among middle aged women in the community. Bri Med J 1988; 296: 959 - 62.

Patrick DL, Deyo RA. Generic and disease specific measures in assessing health status and quality of life. Med Care 1989; 27: S217 - S232. 
Pfeiffer E, Verwoerdt A, Davis G. Sexual behavior in middle life. Am $\mathbf{J}$ Psychiatry 1972; 128: $1262-7$.

Priest $\mathrm{R}$, Crisp A. The menopause and its relationship with reported somatic experiences. In: Morris N, editor. Psychosomatic medicine in obstetrics and gynecology. Basel: Karger; 1972. p. 605 - 7.

Rahe $\mathrm{RH}$, Romo M, Bennett L, Siltanen P. Recent life changes, myocardial infarction and abrupt coronary death Arch Intern Med 1974; 133: 221-8.

Romano BW. Qualidade de vida: teoria e prática. Rev Soc Cardiol Estado São Paulo 1993; 3 (6 supl A): 6 - 9.

Rozanski A, Blumental JA, Kaplan J. Impact of psychological factors on the pathogenesis of cardiovascular disease and implications for therapy. Circulation 1999; 99: $2192-217$.

Schenck-Gustatson K. Risk factors for cardiovascular disease in women: assessment and management. Eur Heart J 1996; 17 supl D: 2-8. 
Sherwin BB. Menopause: Myths and realities. In: Stewart DE, Stotland NL Psychological aspects of women's health care: the interface between psychiatry, obstetrics and gynecology. American Psychiatric Press; 1993.

Schindler BA. The psychiatric disorders of midlife: Med Clin N Am 1987; 71: $127-34$

Schleifer SJ, Macari-Hinson MM, Coyle DA. The nature and course of depression following myocardial infarction. Arch Intern Med 1989; 149: 17859.

Skultans V. The simbolic significance of menstruation and menopause In: Willians JH (organizator). Psychology of women: selected readings. New York: WW Norton \& Company; 1979. 115 - 27.

Thonet C. Climateric: una perspectiva psicomatica. Rev Med Chile 1985; 113: $1222-6$.

Ware JE. Standards for validating health measures: definition and content. J Chron Dis 1987; 40: $473-80$. 
Ware JE, Sherbourne CD. The MOS 36-item short-form health survey (SF-36).

I. Conceptual frame work and item selection. Med Care 1992; 30: 473-83.

Weinbereger M, Oddone EZ, Sausa GP, Landsman PB. Are health related quality of life measures affected by the mode of administration? $\mathbf{J}$ Clin Epidemiol 1996; 49: 135 - 40.

Wenger NK. Epidemiology of coronary heart disease in womem. Rev Soc Cardiol Estado São Paulo 1996; 6: 672 - 80.

WHOQOL Group. The development of the World Health Organization quality of life assesment instrument (The WHOQOL). In: Orley J, Kuyken W, editors. Quality of life assesment: international perspectives. Heidelberg: Springer Verlag; 1994. p. 41-60.

Wilson DH, Taylor AW, MC Lennan AH. Health status of hormone replacement therapy users and non-users as determined by the SF-36 quality of life dimension. Climateric 1998; 1: 50-4.

Winnicott DW. Tudo começa em casa. São Paulo: Martins Fontes; 1989. 
Wong PT. Personal meaning and successful aging. Can Psychol 1989; 30: 516 $-25$. 